\title{
Observations of meteoric material and implications for aerosol nucleation in the winter Arctic lower stratosphere derived from in situ particle measurements
}

\author{
J. Curtius ${ }^{1}$, R. Weigel ${ }^{2}$, H.-J. Vössing ${ }^{1}$, H. Wernli ${ }^{1}$, A. Werner $^{3}$, C.-M. Volk ${ }^{3}$, P. Konopka ${ }^{4}$, M. Krebsbach ${ }^{4}$, \\ C. Schiller ${ }^{4}$, A. Roiger ${ }^{5}$, H. Schlager ${ }^{5}$, V. Dreiling ${ }^{6}$, and S. Borrmann ${ }^{1,2}$ \\ ${ }^{1}$ Institute for Atmospheric Physics, Johannes Gutenberg-University, Mainz, Germany \\ ${ }^{2}$ Max-Planck-Institute for Chemistry, Mainz, Germany \\ ${ }^{3}$ Institute for Meteorology, Johann Wolfgang Goethe-University, Frankfurt, Germany \\ ${ }^{4}$ ICG-2, Research Center Jülich, Jülich, Germany \\ ${ }^{5}$ Institute for Physics of the Atmosphere, German Center for Air and Space DLR, Oberpfaffenhofen, Germany \\ ${ }^{6}$ Flight Facilities, German Center for Air and Space DLR, Oberpfaffenhofen, Germany
}

Received: 20 May 2005 - Published in Atmos. Chem. Phys. Discuss.: 20 July 2005

Revised: 4 October 2005 - Accepted: 3 November 2005 - Published: 15 November 2005

\begin{abstract}
Number concentrations of total and non-volatile aerosol particles with size diameters $>0.01 \mu \mathrm{m}$ as well as particle size distributions $(0.4-23 \mu \mathrm{m}$ diameter) were measured in situ in the Arctic lower stratosphere (10-20.5 km altitude). The measurements were obtained during the campaigns European Polar Stratospheric Cloud and Lee Wave Experiment (EUPLEX) and Envisat-Arctic-Validation (EAV). The campaigns were based in Kiruna, Sweden, and took place from January to March 2003. Measurements were conducted onboard the Russian high-altitude research aircraft Geophysica using the low-pressure Condensation $\mathrm{Nu}$ cleus Counter COPAS (COndensation PArticle Counter System) and a modified FSSP 300 (Forward Scattering Spectrometer Probe). Around $18-20 \mathrm{~km}$ altitude typical total particle number concentrations $n_{t}$ range at $10-20 \mathrm{~cm}^{-3}$ (ambient conditions). Correlations with the trace gases nitrous oxide $\left(\mathrm{N}_{2} \mathrm{O}\right)$ and trichlorofluoromethane $(\mathrm{CFC}-11)$ are discussed. Inside the polar vortex the total number of particles $>0.01 \mu \mathrm{m}$ increases with potential temperature while $\mathrm{N}_{2} \mathrm{O}$ is decreasing which indicates a source of particles in the above polar stratosphere or mesosphere. A separate channel of the COPAS instrument measures the fraction of aerosol particles non-volatile at $250^{\circ} \mathrm{C}$. Inside the polar vortex a much higher fraction of particles contained non-volatile residues than outside the vortex ( $\sim 67 \%$ inside vortex, $\sim 24 \%$ outside vortex). This is most likely due to a strongly increased fraction of meteoric material in the particles which is transported downward from the mesosphere inside the polar vortex. The high
\end{abstract}

Correspondence to: J. Curtius

(curtius@mail.uni-mainz.de) fraction of non-volatile residual particles gives therefore experimental evidence for downward transport of mesospheric air inside the polar vortex. It is also shown that the fraction of non-volatile residual particles serves directly as a suitable experimental vortex tracer. Nanometer-sized meteoric smoke particles may also serve as nuclei for the condensation of gaseous sulfuric acid and water in the polar vortex and these additional particles may be responsible for the increase in the observed particle concentration at low $\mathrm{N}_{2} \mathrm{O}$. The number concentrations of particles $>0.4 \mu \mathrm{m}$ measured with the FSSP decrease markedly inside the polar vortex with increasing potential temperature, also a consequence of subsidence of air from higher altitudes inside the vortex. Another focus of the analysis was put on the particle measurements in the lowermost stratosphere. For the total particle density relatively high number concentrations of several hundred particles per $\mathrm{cm}^{3}$ at altitudes below $\sim 14 \mathrm{~km}$ were observed in several flights. To investigate the origin of these high number concentrations we conducted air mass trajectory calculations and compared the particle measurements with other trace gas observations. The high number concentrations of total particles in the lowermost stratosphere are probably caused by transport of originally tropospheric air from lower latitudes and are potentially influenced by recent particle nucleation.

\section{Introduction}

Stratospheric aerosol particles influence ozone and at least temporarily climate and they are therefore of considerable current interest. They also play an important role for the 
stratospheric sulfur cycle and for transport of meteoric material. The stratospheric background aerosol is mainly composed of sulfuric acid $\left(\mathrm{H}_{2} \mathrm{SO}_{4}\right)$ and water with some inclusions of meteoric material (Junge and Manson, 1961; Bigg et al., 1970; Murphy et al., 1998; Arnold et al., 1998; Cziczo et al., 2001). From their mass spectrometric measurements, Cziczo et al. (2001) concluded that typically half the stratospheric particles contain meteoric iron of 0.5 to 1 weight percent. Renard et al. (2005) report balloon-borne stratospheric extinction measurements. At $\sim 30 \mathrm{~km}$ altitude unexpected spectral structures around $640 \mathrm{~nm}$ wavelength were interpreted as signals from large particles (larger than several hundred nanometers in size) of most likely extraterrestrial origin. Recently, Baumgardner et al. (2004) reported large fractions of light absorbing particles such as soot in the lowermost Arctic stratosphere at altitudes of 9-12 km.

Several balloon-borne (e.g. Hofmann and Rosen, 1985; Hofmann, 1988, 1990; Hofmann et al., 1989) as well as aircraft-borne studies (Wilson et al., 1989, 1990, 1992; Dye et al., 1992; Borrmann et al., 1993, 2000a) of stratospheric background aerosol in the Arctic and Antarctic winter have been performed with condensation nucleus counters (CNC) and optical particle counters. From balloon-borne CNC measurements evidence was found for the formation of new particles in the polar winter stratosphere at altitudes around 2226 km (Hofmann and Rosen, 1985; Hofmann, 1988, 1990; Hofmann et al., 1989). Wilson et al. $(1989,1990,1992)$ confirmed these findings and observed an anti-correlation of the particle mixing ratio with the stratospheric tracer $\mathrm{N}_{2} \mathrm{O}$ for $\mathrm{N}_{2} \mathrm{O}<150$ ppbv. From that they concluded that a source of particles must exist in the Arctic stratosphere.

Furthermore, several model studies that applied classical nucleation theory were able to confirm such particle nucleation in the polar stratosphere from nucleation of sulfuric acid and water (Hamill et al., 1990; Zhao et al., 1995; Mills et al., 1999; Timmreck, 2001). At lower altitudes (9-13 km), Lee et al. (2003) detected recent nucleation events in the Arctic lowermost stratosphere. From a comparison of the measurements with a model by Lovejoy et al. (2004) the nucleation was attributed to ion-induced nucleation of sulfuric acid and water.

Only few investigations have studied the volatility of stratospheric background particles (e.g. Rosen, 1970; Deshler et al., 1993; Brock et al., 1995) and to our knowledge no such study was conducted in the Arctic winter stratosphere. In these volatility experiments the stratospheric aerosol is usually passed through a heated inlet. The temperature of the probed aerosol is thereby raised above the boiling point for $\mathrm{H}_{2} \mathrm{SO}_{4} / \mathrm{H}_{2} \mathrm{O}$ solutions. Particle residuals remaining nonvolatile at these temperatures are counted. From their measurements of total and non-volatile aerosol particles Brock et al. (1995) concluded that new particles are likely to form from $\mathrm{H}_{2} \mathrm{SO}_{4}$ and $\mathrm{H}_{2} \mathrm{O}$ in the tropical tropopause layer and are then transported and distributed by the Brewer-Dobson circulation and by isentropic flow throughout the stratosphere.
They are thought to constitute the major source of the stratospheric aerosol particles on which further gaseous $\mathrm{H}_{2} \mathrm{SO}_{4}$ and $\mathrm{H}_{2} \mathrm{O}$ condenses in the stratosphere (Hamill et al., 1997).

A large fraction of the meteoroides entering the Earth's atmosphere ablate in the mesosphere at altitudes above $75 \mathrm{~km}$. The ablated material composed of elements as iron, magnesium and silicon re-condenses to form nanometer-sized particles termed meteoric smoke (Hunten et al., 1980; Turco et al., 1981; Cziczo et al., 2001; Plane 2003). Numerical models of the mesospheric and stratospheric circulation show that mesospheric air descends rapidly into the stratospheric polar vortex during winter. From these models it is estimated that most of the mesospheric air is funneled into the stratospheric polar vortex every winter (Fisher et al., 1993; Plumb et al., 2003). Observational evidence for a significant fraction of mesospheric air in the lower stratospheric polar vortex comes from CO- $\mathrm{N}_{2} \mathrm{O}$ relation measurements and from air mass ages determined by in situ $\mathrm{CO}_{2}$ and $\mathrm{SF}_{6}$ measurements (Plumb et al., 2003). An enhancement of meteoric smoke particles is therefore expected to occur inside the Arctic vortex (Prather and Rodriguez, 1988; Plane, 2003) and diabatic subsidence of air masses by radiative cooling will transport some of the meteoric material all the way down to $16 \mathrm{~km}(\sim 400 \mathrm{~K})$ by the end of winter (Plumb et al., 2003).

Measurements of particles larger than $\sim 0.3 \mu \mathrm{m}$ in diameter in the polar stratosphere reported a strong decrease of the number concentration of these particles for the Antarctic as well as for the Arctic stratosphere at altitudes $>18 \mathrm{~km}$ (Hofmann et al., 1989; Borrmann et al., 2000a). These measurements are supported by satellite measurements which revealed a reduction in aerosol extinction by more than 1 order of magnitude inside the polar vortex compared to outside (McCormick et al., 1983; Kent et al., 1985; Thomason et al., 1997). As the aerosol extinction is caused by the optically active particles larger than $\sim 0.3 \mu \mathrm{m}$ in diameter these findings are consistent with the in situ measurements. Note that the results from satellite observations are potentially biased as some a priori hypotheses about the shape of the aerosol distribution and the refractive indices have to be included (Renard et al., 2002).

Two automated stratospheric aerosol counters COPAS (COndensation PArticle Counter System) have been built and characterized. These counters were flown aboard the Russian high-altitude research aircraft Geophysica. Here we introduce the COPAS instrument and present particle data from the two recent Arctic measurement campaigns "European Polar Stratospheric Cloud and Lee Wave Experiment - EUPLEX" and "Envisat Arctic Validation - EAV". The campaigns were conducted from 10 January to 19 March 2003, and were based in Kiruna, Sweden. The focus of our studies is on the differences in $\mathrm{CN}$-concentration and $\mathrm{CN}$-volatility inside and outside of the polar vortex. Number concentrations of larger particles $(>0.4 \mu \mathrm{m})$ and aerosol size distributions measured simultaneously aboard Geophysica with an FSSP 300 instrument are discussed. In Sect. 3.4 we focus on 
the observed high variability of particle concentrations measured in the lowermost stratosphere.

\section{Instrumental}

The COPAS instrument is a two channel aerosol counter designed for automated low pressure measurements of the particle number concentration. It is a continuous flow condensation nucleus counter (CNC) operating with 1-butyl alcohol (butanol) as its working fluid. The COPAS instrument has been designed in accordance to the Denver University CNC (Wilson et al., 1983). Downstream from the air intake the flow is split into two subflows: A filtered particle-free subflow is saturated with butanol vapor at $30^{\circ} \mathrm{C}$. Subsequently, sample air containing particles is added to the center of the saturated sheath flow. Then the total flow is cooled to $2^{\circ} \mathrm{C}$ in a condenser. By condensation of butanol vapor the particles grow to sizes $>1 \mu \mathrm{m}$ and are optically detected and counted. Aerosol sample flow and total flow are monitored and controlled by use of calibrated differential pressure sensors. Optimum flow conditions are maintained by use of a regulated pump. A series of laboratory measurements showed that a total counting efficiency close to unity can be achieved by adjusting the flow properly at low pressure conditions.

Data are recorded at $1 \mathrm{~Hz}$, temperatures of the saturator and condenser are controlled within $0.2^{\circ} \mathrm{C}$, measurement uncertainty is $<20 \%$ for stratospheric particle concentrations. The lower cut-off limit (smallest detectable aerosol particle diameter) of the counters has been determined experimentally to be $\sim 10 \mathrm{~nm}$ for sulfuric acid particles and the cutoff is slightly dependent on operating pressure (cf. Hermann and Wiedensohler, 2001). In our laboratory experiments we found the cut-off for the COPAS instrument when operating with butanol and detecting sulfuric acid-water particles to be $9.7 \pm 1.6$ at $70 \mathrm{hPa}, 8.1 \pm 1.7 \mathrm{~nm}$ at $120 \mathrm{hPa}$ and $5.8 \pm 2.0 \mathrm{~nm}$ at $200 \mathrm{hPa}$ for one channel and $9.5 \pm 2.2 \mathrm{~nm}$ at $120 \mathrm{hPa}$ and $7.4 \pm 2.2 \mathrm{~nm}$ at $200 \mathrm{hPa}$ for the other channel. Operation of the instrument and data acquisition are fully automated.

The intake of the sample inlet protrudes outside of the Geophysica's boundary layer and it consists of two serial diffusors which slow down the sample air from the free flow to pumping velocity at near-isokinetic conditions (Wilson et al., 1992). The inlet faces into flight direction and the diffusors are constructed with opening angles of $6.7^{\circ}$ to reduce turbulence losses. Because the number concentration of stratospheric background aerosol during the present volcanically quiescent period is by far dominated by particles with diameters $<0.25 \mu \mathrm{m}$ diameter we consider the sampling to be free of significant losses or enhancements from the inlet.

The first channel of the instrument measures the total number of aerosol particles $n_{t}$. The second channel is heated to $250^{\circ} \mathrm{C}$ before the sample flow enters the instrument and thereby aerosol particles completely volatile at this temperature are evaporated and only the non-volatile fraction $n_{n v}$ is counted. Particles purely composed of sulfuric acid and water are volatile at this temperature. Therefore the difference between the two channels gives an estimate of the fraction of stratospheric particles not composed entirely of sulfuric acid and water. Note that with a 10 -nm cut-off diameter already very small non-volatile residues of originally predominantly volatile particles are counted as non-volatile. For example, a 150-nm particle composed of 99.5 vol.- $\%$ sulfuric acid and water and 0.5 vol.- $\%$ non-volatile residues will leave a residue of approximately $26 \mathrm{~nm}$ diameter which will still be counted. The aerosol heater is a $1 \mathrm{~m} \mathrm{long}, 12 \mathrm{~mm}$ i.d. stainless-steel tube with heating wires and insulation wrapped around the tube. Careful laboratory measurements confirmed that pure sulfuric acid particles of $10-200 \mathrm{~nm}$ diameter are completely evaporated with this heater. For these lab studies we used size-selected, freshly nucleated sulfuric acid particles, generated as described by Middlebrook et al. (1995). We observed that already small contaminations with e.g. ammonia will leave a considerable amount of residual particles and care has to be taken to avoid such contamination (cf. Middlebrook et al., 1995). Diffusion losses in the aerosol heater were calculated to be negligible for particles $>20 \mathrm{~nm}$, and laboratory tests confirmed these calculations. Note that most of the previous studies on particle volatility in the stratosphere used instruments that detect only particles $>0.3 \mu \mathrm{m}$ in diameter. Small residual particles like meteoric smoke particles of a few nanometers in size will not be detected as residual particles by these instruments (Rosen, 1970; Deshler et al., 1993).

Two identical COPAS instruments have been built and we were able to operate both simultaneously onboard of Geophysica for five flights within the EUPLEX project. The two COPAS instruments had separate inlets of identical design and one instrument was placed in a bay in the fuselage of the aircraft, the other was located in an instrument bay under the left wing, behind the landing gear compartment. Only one aerosol heater was installed, therefore a total of one heated and three unheated channels was available for these flights. For future measurement campaigns it is planned to operate the three unheated channels with different saturator temperatures to allow for different cut-off diameters enabling the identification and sizing of freshly nucleated ultrafine particles (Brock et al., 2000).

A scatter plot of the two unheated channels of the second COPAS instrument is shown in Fig. 1a and a plot of channel 1, COPAS 1, versus channel 1, COPAS 2, is shown in Fig. 1b for the data of the EUPLEX flights. The two channels of the COPAS 2 instrument agree very well over the entire measurement range and a linear regression yields a slope of 1.003, an offset of -0.03 and $r^{2}=0.996$. The two unheated channels of the different instruments still agree well but the correlation is not as good (slope $=0.95$, offset $\left.=0.1, \mathrm{r}^{2}=0.985\right)$. Some of the scatter in Fig. 1b is caused by the fact that we were only able to synchronize the COPAS 2 system clock with the universal aircraft clock, but due to technical problems not the 

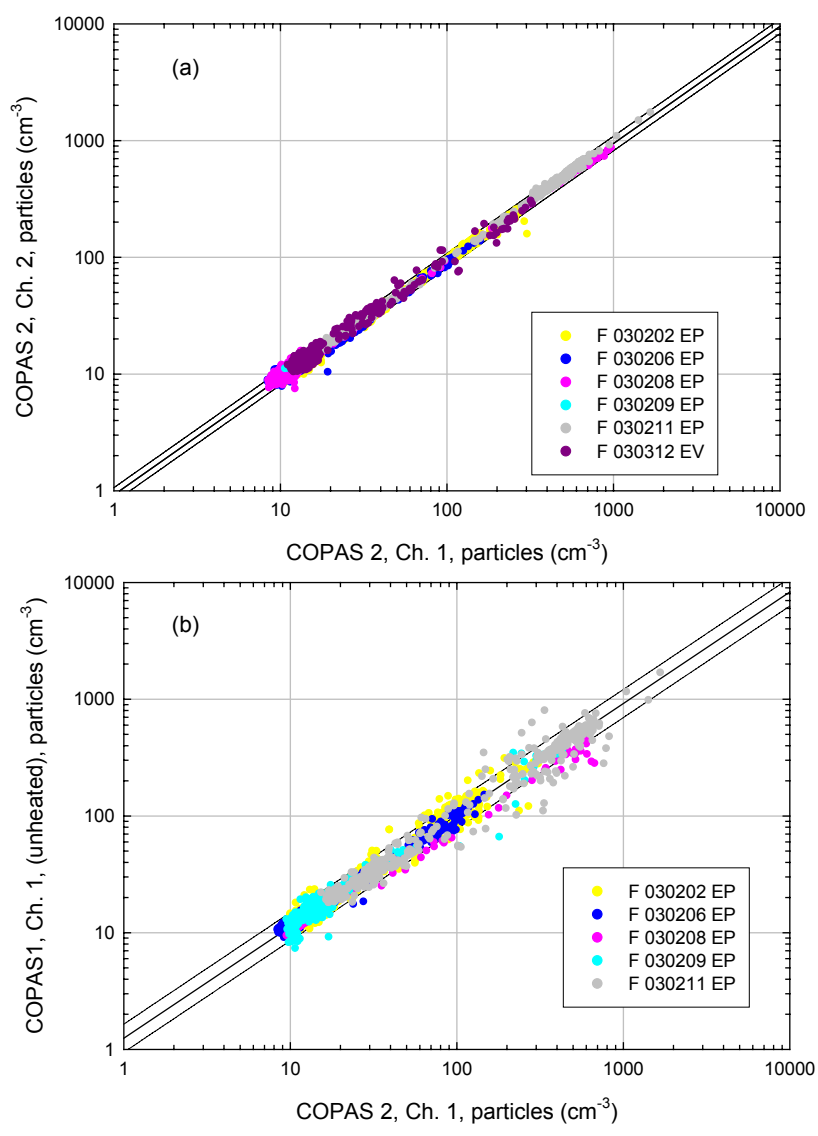

Fig. 1. Comparison of total particle concentration measurements $\mathrm{n}_{t}$ (15-s averages) by the two unheated channels of COPAS 2 including a linear regression and $95 \%$ prediction intervals (a). Comparison of particle concentration measurements by unheated channel of COPAS 1 and unheated channel of COPAS 2 including a linear regression and $95 \%$ prediction intervals for the five EUPLEX flights when both instruments were operated simultaneously (b).

COPAS 1 clock, which caused slight shifts in the occurrence of distinct concentration features and degraded the correlation. We include the $95 \%$ prediction interval in Fig. 1. For Fig. 1a a pair of data points falls with $95 \%$ probability in an interval $\pm 14 \%$ around the regression line, and for Fig. $1 \mathrm{~b}$ the $95 \%$ prediction interval is $\pm 22 \%$, respectively. We give particle concentrations usually as number of particles per cubic centimeter at ambient temperature and pressure conditions. Only for the correlation with the trace gases $\mathrm{N}_{2} \mathrm{O}$ and $\mathrm{CFC}$ 11 particle mixing ratios are presented as particles per $\mathrm{mg}$ of air to allow for direct comparison with other publications.

The modified Forward Scattering Spectrometer Probe SPP-300 (FSSP-SPP 300) operated on Geophysica measures the size distribution of aerosol particles between 0.4 and $23 \mu \mathrm{m}$. The instrument has been described in detail before (Baumgardner et al., 1992; Borrmann et al., 2000a, b; Thomas et al., 2002). However for the configuration as utilized on Geophysica during EUPLEX and EAV the original electronics were replaced by the Signal Processing Package (SPP) by Droplet Measuring Systems Inc. In addition, the computer for data acquisition and instrument control was integrated into the cylindrical standard instrument container which is mounted below Geophysica's left wing. In this way no separate data acquisition system box is required which considerably reduces radio frequency interference and noise contamination problems. In order to accommodate the ambient conditions of temperatures as low as $-90^{\circ} \mathrm{C}$ and pressures down to $50 \mathrm{hPa}$ specialized thermal control was also implemented within the FSSP-SPP-300 cylinder. In this new configuration the FSSP-SPP-300 has a resolution of up to 40 size bins. The bin limits can be switched to different refractive indices by software control. The instrument's sampling rate is $0.5 \mathrm{~Hz}$ but for the low number concentrations of particles $>1 \mu \mathrm{m}$ in the stratosphere during volcanically quiescent times typically $30 \mathrm{~min}$ of data are integrated to derive particle size distributions with good counting statistics.

$\mathrm{N}_{2} \mathrm{O}$ and CFC-11 are measured by the high accuracy gas chromatograph HAGAR (High Altitude Gas Analyser, Volk et al., 2005 ${ }^{1}$ ). Ozone is measured using the Fast Ozone UV absorption Experiment (FOX). The Fast In situ Stratospheric Hygrometer (FISH) for the measurement of total water is based on the Lyman- $\alpha$ photofragment fluorescence technique. Details of the instrument and the calibration procedure are described by Zöger et al. (1999).

\section{Measurements and discussion}

\subsection{Total particle concentration}

Vertical profiles of the total particle concentration $n_{t}$ for 14 flights of the EUPLEX and EAV-campaigns are shown in Fig. 2. Ambient particle concentrations are typically 10 $20 \mathrm{~cm}^{-3}$ at $18-20 \mathrm{~km}$ altitude. The concentration ranges are in good agreement with measurements by other authors for the Arctic winter stratosphere (e.g. Hofmann, 1990). Open circles indicate median average particle concentrations binned by $500 \mathrm{~m}$ altitude intervals. Error bars designate the 25- and 75-percentiles of the averaged data in each altitude bin. Below $18 \mathrm{~km}$ number concentrations are increasing with decreasing altitude. For instance, on 23 January and 6 February this increase is relatively smooth and particle concentrations below $100 \mathrm{~cm}^{-3}$ are measured throughout the lowermost stratosphere (LS). In contrast, $n_{t}$ increases markedly to concentrations of several hundred particles per $\mathrm{cm}^{3}$ below $\sim 14 \mathrm{~km}$ during several other flights (e.g. 8 and 28 February). The origin of these structures will be discussed in detail in Sect. 3.4.

\footnotetext{
${ }^{1}$ Volk, C. M., Werner, A., Wetter, T., Ivanova, E., Wollny, A., Ulanovsky, A., Ravegnani, F., Schlager, H., Konopka, P., and Toon, G.: Ozone loss within the 2003 Arctic vortex derived from in situ observations with the Geophysica aircraft, Atmos. Chem. Phys. Discuss., in preparation, 2005.
} 


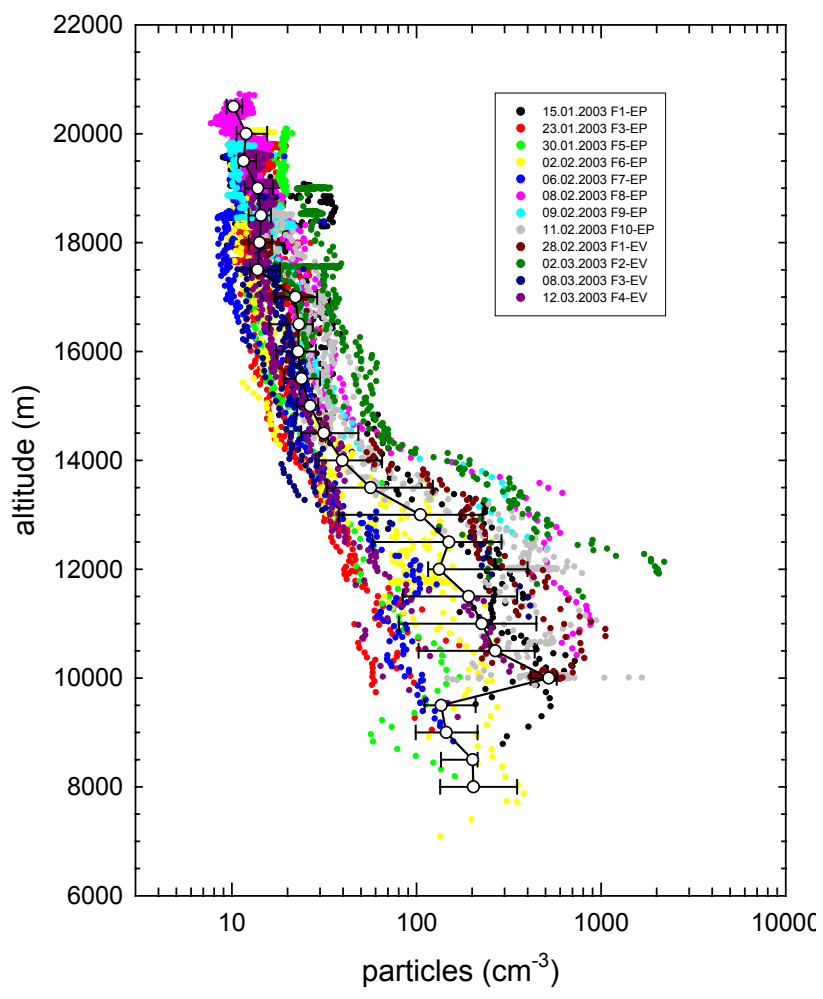

Fig. 2. Vertical profiles of total particle concentrations $\mathrm{n}_{t}$ for all flights within the EUPLEX and EAV measurement campaigns. Data points are 15-s averages. Median values over all data binned in $500 \mathrm{~m}$ altitude intervals are included. Error bars denote the 25- and 75-percentiles. Several flights revealed a sharp increase in particle concentration at altitudes below $\sim 14 \mathrm{~km}$ (e.g. flight of 8 February 2003), whereas other flights did not show such pronounced structures (e.g. flight of 23 January 2003).

Figure 3 displays $n_{t}$ as a function of potential temperature $(\Theta)$. In general, the particle data follows a fairly compact correlation, decreasing with increasing $\Theta$ until a broad minimum around $400-460 \mathrm{~K}$ is reached. For higher $\Theta$ the particle concentration increases, reaching $15-20 \mathrm{~cm}^{-3}$ for the highest $\Theta$ values above $460 \mathrm{~K}$.

In order to distinguish air masses measured inside and outside the polar vortex we use the artificial vortex tracer calculated by the three-dimensional Chemical Lagrangian Model of the Stratosphere (CLaMS). CLaMS is a model to study transport and mixing processes of tracers in the stratosphere (McKenna et al., 2002; Konopka et al., 2004). The CLaMS model allows, for example, to quantify the vortex dilution over the course of the winter and to trace the mixing across the vortex edge into the vortex to particular dynamical properties of the stratospheric flow (Steinhorst et al., 2005). In the CLaMS model the vortex edge is commonly defined by the strongest gradient in potential vorticity (PV) (Nash et al., 1996). In CLaMS, the dilution of the vortex is calculated by introduction of an artificial tracer that at the beginning of

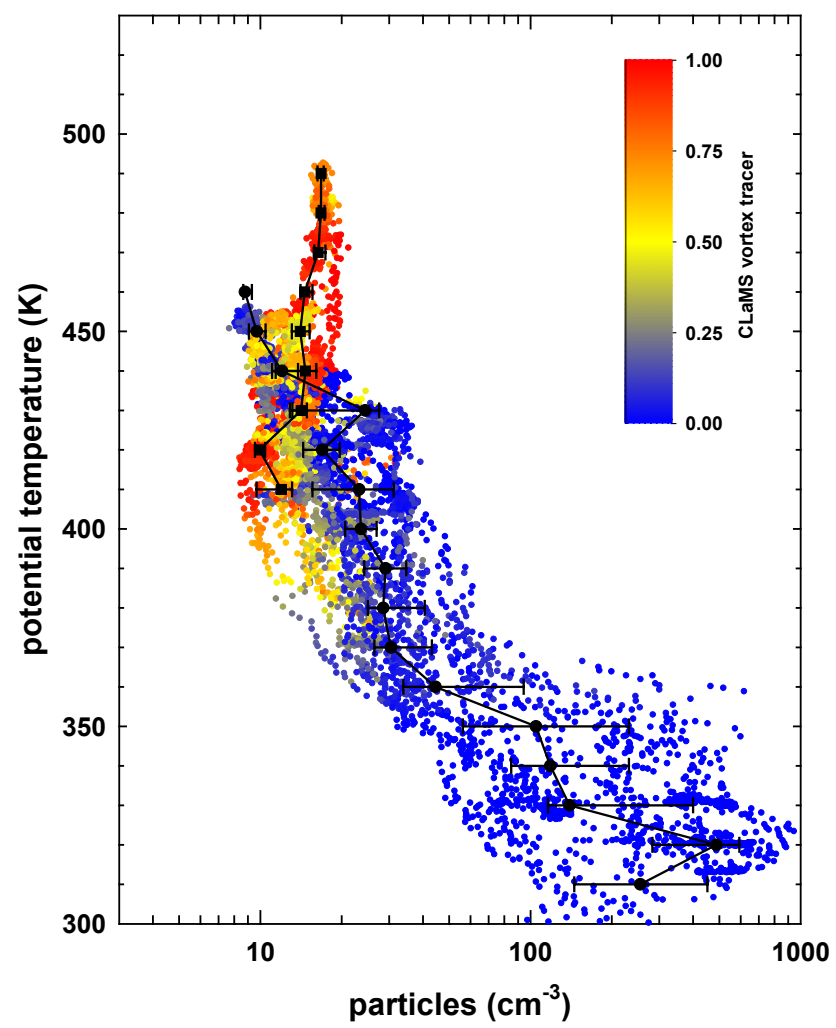

Fig. 3. Particle concentration $\mathrm{n}_{t}$ as a function of potential temperature. Inside vortex (CLaMS Vortex tracer $>0.75$, squares) and outside vortex (CLaMS vortex tracer $<0.25$, circles) median values over the data binned in intervals of $10 \mathrm{~K}$ with 25 - and 75-percentiles (error bars) are included. Values of the CLaMS vortex tracer are color coded.

the model run (1 December) labels the air parcels inside and outside the vortex by 100 and $0 \%$, respectively. This tracer describes the percentage of the pure vortex air defined in this way in each air parcel throughout the winter. The CLaMS artificial vortex tracer has been calculated for the air parcels encountered in the Geophysica measurement flights. It allows a convenient distinction of air mass encounters inside and outside the vortex and mixing processes across the vortex edge can be studied. In Fig. 3 the value of the vortex tracer is indicated by color coding. Median values of $n_{t}$ have been calculated for data observed inside the vortex (CLaMS vortex tracer $>0.75$ ) and extra-vortex data (ClaMS vortex tracer $<0.25)$. Distinct differences are observed: Outside the vortex, $n_{t}$ decreases continiously with increasing $\Theta$, while a positive correlation is observed inside the vortex. For identical $\Theta$ values the median number concentrations differ considerably indicating the transport barrier for isentropic flow across the vortex edge.

Comparing the total particle number mixing ratio with the simultaneously measured trace gases nitrous oxide $\left(\mathrm{N}_{2} \mathrm{O}\right)$ and trichlorofluoromethane (CFC-11) allows some further allocation and quantification of air mass origin. In our 

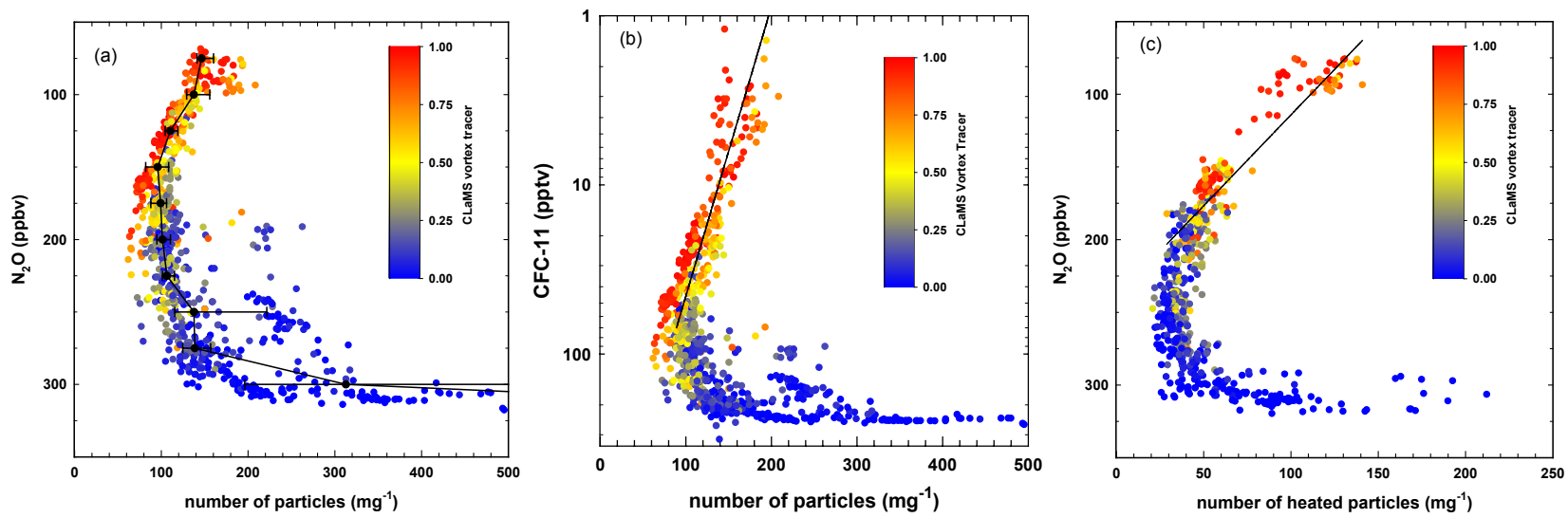

Fig. 4. Correlation of $\mathrm{N}_{2} \mathrm{O}$ mixing ratios and total particle mixing ratio given as number of particles per mg of air. Values of the vortex tracer are color coded. Median values binned by $20 \mathrm{ppbv}$ of $\mathrm{N}_{2} \mathrm{O}$ as well as 25 - and 75-percentiles are included (a). Correlation of CFC-11 mixing ratios and particle mixing ratios including a regression line for CFC-11<70 pptv (a). Correlation of $\mathrm{N}_{2} \mathrm{O}$ with non-volatile particle mixing ratios including a regression line for $\mathrm{N}_{2} \mathrm{O}<200$ ppv (c).Data from flights as indicated in Fig. 1, except for flights, 30 January and 9 February, when HAGAR instrument was not operational; for (c) also data from entire flight of 12 March, and some parts of flights on 8, and 11 February and 8 March when the heated aerosol channel was not operational are missing.

measurements $\mathrm{N}_{2} \mathrm{O}$ and $\mathrm{CFC}-11$ were measured on a $90 \mathrm{~s}$ time basis and corresponding particle concentrations were selected. Figure 4 displays the particle measurements in units of particle number per mg air to be able to compare directly two mixing ratio type quantities and to make our measurements comparable to previous measurements by other authors (Wilson et al., 1989, 1992). The $\mathrm{N}_{2} \mathrm{O}$-particle relation given in Fig. 4a is similar to the $\Theta$-particle relationship. The particle concentration $n_{t}$ decreases sharply with decreasing $\mathrm{N}_{2} \mathrm{O}$ in the lowermost stratosphere (300-240 ppbv $\mathrm{N}_{2} \mathrm{O}$ ). A broad minimum exists with particle concentrations around $100 \mathrm{mg}^{-1}$ for $\mathrm{N}_{2} \mathrm{O}$ of $150-220$ ppbv. For $\mathrm{N}_{2} \mathrm{O}<150$ ppbv an anti-correlation exists with the particle mixing ratio reaching average values of $160 \mathrm{mg}^{-1}$ at $80 \mathrm{ppbv} \mathrm{N}_{2} \mathrm{O}$.

$\mathrm{N}_{2} \mathrm{O}$ and CFC-11 are both trace gases that have sources at ground and are inert in the troposphere. Sink processes in the stratosphere are photodissociation and reaction with $\mathrm{O}\left({ }^{1} \mathrm{D}\right)$ for $\mathrm{N}_{2} \mathrm{O}$ and photolysis for CFC-11. Therefore both tracers generally decrease in the stratosphere with increasing potential temperature. The primary source of particles in the stratosphere is thought to be nucleation of $\mathrm{H}_{2} \mathrm{SO}_{4} / \mathrm{H}_{2} \mathrm{O}$ particles in the tropical tropopause layer (TTL). In general, no nucleation of particles occurs in the stratosphere during volcanically quiescent periods (e.g. Brock et al., 1995; Hamill et al., 1997) except for the nucleation processes in the polar vortex to be discussed here and potentially nucleation in the lowermost stratosphere. Therefore the total particle number mixing ratio decreases to values below $100 \mathrm{mg}^{-1}$ in the stratosphere above $\Theta=460 \mathrm{~K}$ due to coagulation processes (e.g. Brock et al., 1995). Particles are also considered to evaporate at the higher temperatures in the upper stratosphere (e.g. Hamill 1997). Therefore an anti-correlation of decreasing $\mathrm{N}_{2} \mathrm{O}$ and increasing particle mixing ratio while $\Theta$ (Fig. 3) is increasing is indicative of a particle source in the above polar vortex stratosphere or the mesosphere. It can be excluded that particles originally produced in the TTL are the cause of such an anti-correlation as coagulation brings the particle number mixing ratios already down to values around or below $100 \mathrm{mg}^{-1}$ in the tropical stratosphere for $\Theta>460 \mathrm{~K}$ (Brock et al., 1995).

Our data supports the findings by Hofmann $(1988,1990)$ who observed layers of enhanced particles in the Arctic as well as the Antarctic polar vortex at altitudes of $\sim 22-26 \mathrm{~km}$, which were attributed to new particle formation, probably by sulfuric acid and water. The conditions for homogeneous nucleation of new particles are favorable in the polar vortex because temperatures are very low, the pre-existing aerosol surface area is small (see Sect. 3.3), and gaseous $\mathrm{H}_{2} \mathrm{SO}_{4}$ which has evaporated from particles at higher temperatures in the upper stratosphere is expected to be supersaturated when subsiding inside the polar vortex (Schlager and Arnold, 1987). Here, for a quantitative assessment, also the stratospheric cycling of gaseous $\mathrm{H}_{2} \mathrm{SO}_{4}$ and $\mathrm{SO}_{2}$ would have to be considered as gaseous $\mathrm{H}_{2} \mathrm{SO}_{4}$ actually absorbs nearinfrared radiation in the upper stratosphere or mesosphere through $\mathrm{OH}$ stretching vibrational overtone transitions that lead to photolysis of $\mathrm{H}_{2} \mathrm{SO}_{4}$ forming $\mathrm{SO}_{3}$ which is rapidly photolyzed yielding $\mathrm{SO}_{2}$ (Vaida et al., 2003). The $\mathrm{SO}_{2}$ (not supersaturated) then may be transported downward by subsidence inside the Arctic vortex and is eventually transformed back into gaseous $\mathrm{H}_{2} \mathrm{SO}_{4}$ by $\mathrm{OH}$ reaction at the end of the polar night, yielding the required super-saturations for nucleation to occur (Zhao et al., 1995). 
Besides homogeneous nucleation other processes have to be considered: conditions for ion-induced nucleation are favorable as the atmospheric ion density produced from galactic cosmic rays is highest at altitudes of $15-25 \mathrm{~km}$ (Rosen et al., 1985; Lovejoy et al., 2004). It is furthermore conceivable that the gaseous $\mathrm{H}_{2} \mathrm{SO}_{4}$ condenses on nanometer-sized meteoric smoke particles that are brought into the polar vortex from the mesosphere (Hunten et al., 1980; Zhao et al., 1995, see following section). Because the number of particles produced by homogeneous nucleation is a very nonlinear function of temperature and supersaturation, it would be surprising to measure such a compact correlation of $\mathrm{N}_{2} \mathrm{O}$ and $n_{t}$ throughout the Arctic winter stratosphere at different times and locations. Therefore a heterogeneous process like ion-induced nucleation or condensation of sulfuric acid and water on meteoric smoke seems more likely to produce such a compact correlation because in these processes the number of nuclei (core ions or ultrafine meteoric smoke particles) is limiting for the number of particles produced and the number of these particles is therefore expected to vary less throughout the polar vortex. As will be discussed in the following section, a heterogeneous condensation on the abundant meteoric smoke particles may be the most likely process.

Our findings for the $\mathrm{N}_{2} \mathrm{O}$-particle correlation are comparable to the correlation for the winter Arctic stratosphere as described by Wilson et al. (1990). These authors also observed an increase of particles with decreasing $\mathrm{N}_{2} \mathrm{O}$ for $\mathrm{N}_{2} \mathrm{O}<150$ ppbv and the general shape of the correlation for the entire range of $\mathrm{N}_{2} \mathrm{O}$ mixing ratios is similar. A difference to the Wilson et al. measurements is that our measurements seem to be shifted to somewhat higher particle mixing ratios: Wilson et al. observe a particle mixing ratio of $50-70 \mathrm{mg}^{-1}$ for $150-220 \mathrm{ppbv} \mathrm{N}_{2} \mathrm{O}$ whereas we observe a minimum of $80-100 \mathrm{mg}^{-1}$ for $150-220 \mathrm{ppbv}$ of $\mathrm{N}_{2} \mathrm{O}$. The reason for these differences might be the different levels in the stratospheric background concentration of particles in years not influenced by volcanic disturbances (Deshler et al., 2003). Additionally, Wilson et al. (1990) observed a shift in the correlation with time: In February average $\mathrm{CN}$ mixing ratios were measured to be $\sim 30 \%$ higher than in January for corresponding $\mathrm{N}_{2} \mathrm{O}$. Such a shift in the $\mathrm{N}_{2} \mathrm{O}$-particle correlation was not observed in our measurements.

The particle mixing ratio as a function of the tracer CFC11 is shown in Fig. 4b. The appearance is similar to the $\mathrm{N}_{2} \mathrm{O}$-particle correlation depicted in Fig. 4a. This can be expected as CFC-11 and $\mathrm{N}_{2} \mathrm{O}$ are closely correlated stratospheric tracers (Plumb and Ko, 1992). Again it is observed that inside the polar vortex the particle mixing ratio increases with decreasing CFC-11 for CFC-11 smaller than $\sim 70$ pptv. A regression of the form $\left[n_{t}\right]=-\mathrm{a} \ln [\mathrm{CFC}-11]+\mathrm{b}$ for CFC$11<70$ pptv has been fitted to the data as displayed in Fig. $4 \mathrm{~b}$ $(a=25.4, b=196.8)$. This increase of particles with decreasing CFC-11 gives further evidence for a source of particles in the above polar vortex. In how far this correlation is typical for the Arctic winter stratosphere in general during volcanically undisturbed times might be an interesting issue of further investigations.

The mixing ratio of non-volatile particles as a function of $\mathrm{N}_{2} \mathrm{O}$ is shown in Fig. 4c for comparison. Similar to the total particles, the non-volatile particles increase markedly inside the vortex with decreasing $\mathrm{N}_{2} \mathrm{O}$ for $\mathrm{N}_{2} \mathrm{O}<200$ ppbv. A detailed discussion of this correlation will be given in the following section.

Some of the particle data shown in Fig. 4 deviate markedly from the otherwise compact correlation: A subset of particle measurements at $\sim 200$ and $\sim 250$ ppbv $\mathrm{N}_{2} \mathrm{O}$ range above $200 \mathrm{mg}^{-1}$. These data points have all been measured during the flight of 2 March 2003. Similarly these elevated data show up in Fig. 3 as elevated particle concentrations around 410 and $425 \mathrm{~K}$, somewhat offset to the remaining data. Although the housekeeping data gave no indication of any instrumental problems, a malfunction such as a leak might be responsible for these data points, outside of the correlation measured in all other flights before and after.

\subsection{Non-volatile particles}

The fraction $f$ of non-volatile residual particles is the ratio of non-volatile particles $n_{n v}$ to all particles $n_{t}$. Measurements of $f$ for all flights of the EUPLEX and EAV campaigns in which the aerosol heater of COPAS was operational are displayed in Fig. 5. The fraction of non-volatile particles covers a wide range of values between 4 and 80 percent indicating differences in the chemical composition of these particles. Corresponding CLaMS vortex tracer values are indicated by color coding. The fraction $f$ of non-volatile particles is strongly dependent on whether the data was obtained inside or outside of the polar vortex. Median values of $f$ inside and outside the vortex (vortex tracer $>0.75$ and $<0.25$ ) have been calculated for $500 \mathrm{~m}$ interval bins. Medians range at $20-30 \%$ outside and $60-70 \%$ inside the vortex.

We assume the explanation for this marked increase in $f$ is that the fraction of particles containing meteoric material is increased inside the polar vortex. The meteoric material is composed to a large degree of refractory components such as oxides of iron, magnesium and silicon. Numerical models show that a large fraction of mesospheric air descends into the polar vortex and an increase of meteoric debris in the Arctic vortex can therefore be expected (Prather and Rodriguez, 1988; Fisher et al., 1993; Plumb et al., 2003). As argued in the instrumental section, already a weight fraction of $0.5 \%$ of non-volatile material is sufficient for the particles to be classified as non-volatile by our $\mathrm{CN}$-Counter. Nevertheless, the marked differences for data obtained inside and outside the polar vortex at identical altitude indicate a substantial difference in background aerosol composition. This difference might influence the formation of polar stratospheric clouds (Voigt et al., 2005), aerosol alkalinity (Prather and Rodriguez, 1988) or play a role in polar stratospheric aerosol nucleation. It is also interesting to note that a major fraction 


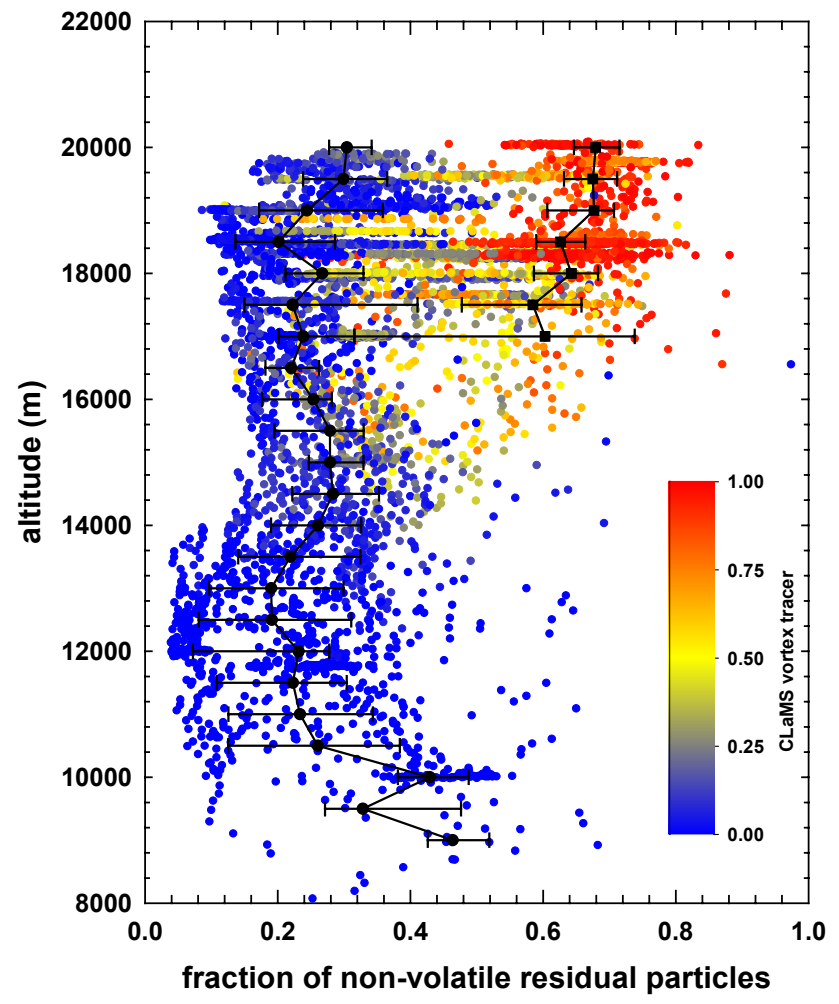

Fig. 5. Fraction $f$ of non-volatile residual particles (ratio of nonvolatile residual particles $\mathrm{n}_{n v}$ to total particle concentration $\mathrm{n}_{t}$ ) as altitude profile with vortex tracer indicated by color coding (a). Data from flights as indicated in Fig. 1, except for entire flight of 12 March, and some parts of flights on 8, 9, and 11 February and 8 March when $\mathrm{CN}$-Counter with heated aerosol channel was not operational.

of the meteoric smoke particles therefore bypasses most of the extra-vortex stratosphere when being transported from the mesosphere to the ground. When the vortex breaks up a significant fraction of the mesospheric air parcels is released in the lower stratosphere at high latitudes and will then be mixed eventually into the troposphere by stratospheretroposphere transport processes. Calculations determining the total influx of extraterrestrial material based on measurements in the mid-latitude stratosphere are therefore possibly underestimates (Cziczo et al., 2001).

Gabrielli et al. (2004) study iridium and platinum concentrations in Greenland ice cores. A major fraction of the $\mathrm{Ir}$ and $\mathrm{Pt}$ is found to have an extraterrestrial origin. Due to the focusing effect of the meridional circulation in the mesosphere and the downward transport of meteoric smoke particles in the polar vortex an enhancement of cosmic material deposited at the Earth surface poleward of $55^{\circ}$ latitude is postulated, in comparison to the global average assuming a uniform influx. Our conclusion of the enhanced non-volatile material in the vortex being meteoric smoke particles therefore supports these findings, and vice versa our findings are supported by the Gabrielli et al. (2004) study.
It is conceivable that the higher concentrations of meteoric material influence the particle nucleation described in Sect. 3.1. Meteoric smoke particles of a few nanometers size form from the re-condensation of the ablated silicon oxides and metallic vapor compounds in the mesosphere. Ablation and smoke particle formation from the low-volatility vapors occurs mostly at altitudes of $80-100 \mathrm{~km}$. The average initial size of the smoke particles at these altitudes is very uncertain. Hunten et al. (1980) estimate a range of 0.4-20 nm diameter and choose a value of $2.6 \mathrm{~nm}$ as the nominal case for their model simulations. Once formed, the particles grow by coagulation and by condensation of further ablated vapors in the mesosphere. Recent calculations with a one-dimensional model describe the development of the meteoric smoke particles in the mesosphere including processes of formation, coagulation, condensation and gravitational settling (Gabrielli et al., 2004). At $60 \mathrm{~km}$ altitude particle concentrations of $\sim 700 \mathrm{~cm}^{-3}$ for particles of $0.4 \mathrm{~nm}$ size to $\sim 20 \mathrm{~cm}^{-3}$ for particles $>4 \mathrm{~nm}$ are modelled. In the stratosphere these smoke particles may serve as heterogeneous nuclei for the condensation of gaseous $\mathrm{H}_{2} \mathrm{SO}_{4}$ or they might coagulate with existing $\mathrm{H}_{2} \mathrm{SO}_{4} / \mathrm{H}_{2} \mathrm{O}$ particles. If the meteoric smoke particles grow to sizes larger than our cut-off diameter of $10 \mathrm{~nm}$ before coagulation with the stratospheric background $\mathrm{H}_{2} \mathrm{SO}_{4} / \mathrm{H}_{2} \mathrm{O}$ particles these additional particles are potentially responsible for the observed increase in total particle concentration (Sect. 3.1), making the nucleation process rather a heterogeneous than a homogeneous one. Zhao et al. (1995) discuss the possible influence of meteoric smoke particles on the polar stratospheric nucleation and their model results indicate that depending on the (uncertain) number concentration of the smoke particles and their ability to act as condensation nuclei for sulfuric acid and water the heterogeneous process can potentially explain the observed nucleation. A remaining question is whether the meteoric smoke particles coagulate fast enough with each other during their downward transport in the Arctic vortex to reach sizes larger than $\sim 10 \mathrm{~nm}$ to be detectable by our $\mathrm{CN}$-counter. A detailed modelling of the coagulation of the meteoric smoke particles with each other, simultaneous coagulation with stratospheric sulfuric acid-water aerosol and condensation of gaseous sulfuric acid and water vapor is beyond the scope of this study, but the time scales of several month are reasonable for at least a fraction of the meteoric smoke particles to reach sizes of the nonvolatile cores of $>10 \mathrm{~nm}$.

Very recently, Engel et al. (2005) published balloon-borne tracer observations $\left(\mathrm{SF}_{6}, \mathrm{CO}, \mathrm{CO}_{2}\right.$, etc. $)$ and model calculations describing the transport of mesospheric air in the Arctic vortex in the winter 2002/2003. They find comprehensive evidence for the presence of mesospheric air in the polar vortex. Interestingly, the largest fraction of mesospheric air is found in a layered structure descending from $\sim 30 \mathrm{~km}$ altitude in January to $\sim 22 \mathrm{~km}$ altitude in March. This observation of a distinct layer of mesospheric air might also explain the $\mathrm{CN}$ layers observed by Hofmann $(1988,1990)$ in the polar vortex 
to be in fact layers of meteoric smoke particles, rather than freshly nucleated sulfuric acid water particles. Furthermore, the results by Engel et al. (2005) support our hypothesis that meteoric smoke particles of mesospheric origin cause the observed enhancement of the non-volatile particle fraction in the Arctic vortex. Due to additional gravitational settling, the meteoric smoke particles, at least the largest ones, are potentially transported downward in the vortex even faster, reaching lower altitudes earlier than the corresponding mesospheric gaseous compounds.

In principle, the slope of the $\mathrm{N}_{2} \mathrm{O}$-non-volatile particle correlation for $\mathrm{N}_{2} \mathrm{O}<200 \mathrm{ppbv}$ (cf. Fig. 4c) could be used to obtain a global source strength of the extraterrestrial influx through meteoric smoke particles (Murphy and Fahey, 1994). We did not apply this concept here as we do not know in how far the observed correlation from inside the polar vortex is representative for the stratosphere in general (e.g. meridionally inhomogeneous influx from the mesosphere could change the correlation at lower latitudes) and because we do not know about the average size and density of the meteoric smoke particles from our measurements which would be necessary to determine the extraterrestrial mass influx.

In Fig. 6 the value of $f$ is shown in relation to the CLaMS artificial vortex tracer. It can be seen that a linear correlation with the measured fraction of non-volatile residual particles exists. Outside the polar vortex, where the vortex tracer is $0 \%$, the value of $f$ is $24 \%$ on average, increasing to an average of $67 \%$ for pure vortex air (vortex tracer $=100 \%$ ). Here the measurements are color coded according to potential temperature. Within limits, $f$ can be viewed as a directly measurable vortex tracer, but because the correlation with the calculated vortex tracer has a substantial scatter, $f$ does not allow a vortex identification as precise as identification from traditional correlations of long-lived gaseous tracers. We found the ratio $f$ to be better suitable as a vortex tracer than the concentration or mixing ratio of the nonvolatile particles alone. For the total particle concentration as well as for the non-volatile concentration a distinct dependence on the vertical coordinate (altitude, potential temperature, $\mathrm{N}_{2} 0$, etc.) exists. For example, measured values of the mixing ratio of non-volatile particles outside the vortex at low potential temperatures can be identical to mixing ratios inside the vortex at higher potential temperatures (cf. Fig. 4c) and therefore a vortex tracer is more difficult to discern. For the ratio $f$ the dependence on the vertical coordinate apparently cancels out and the simple correlation is found. Some of the scatter might be caused by variable numbers of volatile particles (e.g. enhancement due to mixing with air containing newly formed volatile particles from the tropical tropopause region), or to the fact that non-volatile particles are not necessarily all of meteoric origin (e.g. particles such as soot can influence the measurement of the non-volatile particles).

We are confident that the differences in our measurements of $f$ are not due to any instrumental artifact because we tested carefully the efficiency of the aerosol heater to com-

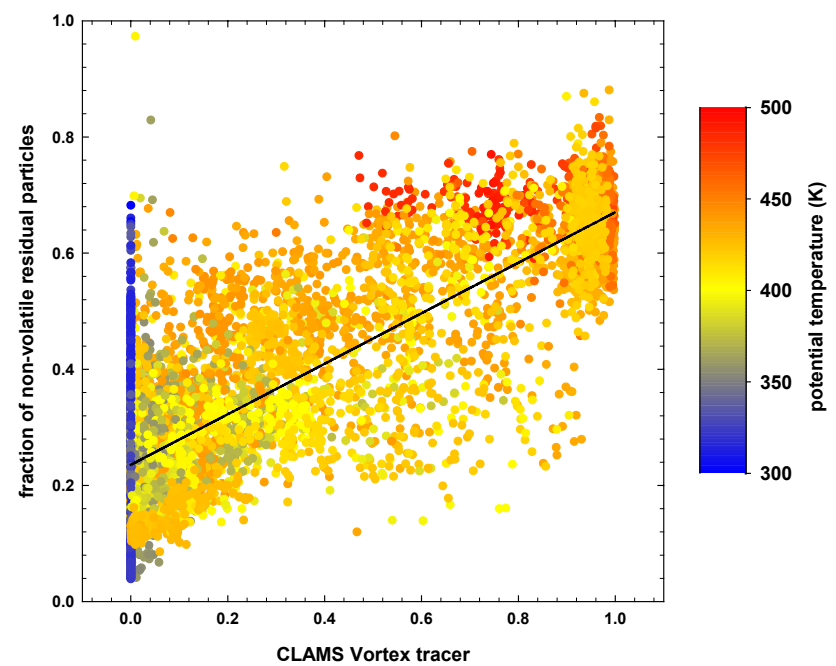

Fig. 6. Fraction $f$ of non-volatile residual particles versus the value of the CLAMS model vortex tracer. Potential temperature values indicated by color coding. A linear regression is included.

pletely evaporate pure sulfuric acid particles in the laboratory. Furthermore, the aerosol size distribution inside the polar vortex is shifted towards smaller particles (see following section) and smaller particles evaporate faster than larger ones of identical composition which makes an instrumental effect unlikely that results in an increase of $f$ inside the vortex. Thus we conclude that the fraction of meteoric material in stratospheric particles at similar altitudes is distinctly higher inside the Arctic vortex compared to outside.

\subsection{Particles $>0.4 \mu \mathrm{m}$}

The concentration of particles $>0.4 \mu \mathrm{m}\left(n_{0.4}\right)$ as a function of altitude is displayed in Fig. 7.

Data from all flights in which the FSSP-300 was operated are shown as 15-s averages. At altitudes between 11 and $16 \mathrm{~km} n_{0.4}$ is typically $0.2-1.0 \mathrm{~cm}^{-3}$. At higher altitudes and inside the Arctic vortex the concentration varies over a much broader range with lowest concentrations near $0.001 \mathrm{~cm}^{-3}$ and maximum concentrations of $0.5 \mathrm{~cm}^{-3}$.

Potential vorticities for the position of the Geophysica during the measurement flights have been interpolated from operational ECMWF analysis data at full resolution. The relation between PV and the mixing ratio of particles $>0.4 \mu \mathrm{m}$ is shown in Fig. 8. The data are displayed as particles per $\mathrm{mg}$ of air, as mixing ratio type quantities are more conserved quantities with potential vorticity than concentrations. Outside the polar vortex the mixing ratio of particles $>0.4 \mu \mathrm{m}$ increases from $\sim 0.5$ to $1.5 \mathrm{mg}^{-1}$ for PV increasing from 2 to $10 \mathrm{pvu}$. It stays relatively constant at $\sim 1.8 \mathrm{mg}^{-1}$ for PV ranging from 12 to 22 pvu. Inside the vortex for $P V \geq 24$ pvu, the particle mixing ratio decreases considerably with increasing PV to values below $0.1 \mathrm{mg}^{-1}$ at $\mathrm{PV}>45 \mathrm{pvu}$. Subsidence inside 


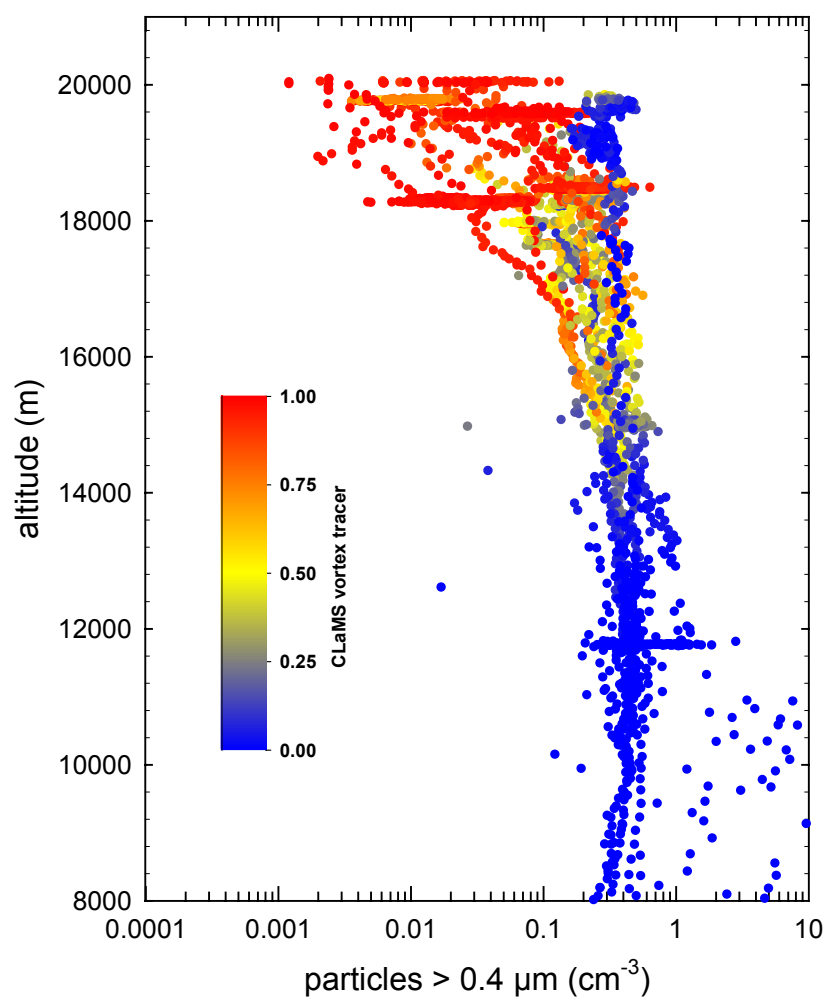

Fig. 7. Number concentration of particles with diameters $>0.4 \mu \mathrm{m}$ (15-s averages) measured with the FSSP-300 as a function of altitude. Vortex tracer values indicated by color coding. Data from flights on 23 and 30 January, and 2, 6, and 8 February when the FSSP-300 was operated are shown.

the vortex is likely to explain the observed decrease. Within the Arctic vortex air masses are sampled which have been transported downward from above the Junge layer containing therefore very low mixing ratios of particles $>0.4 \mu \mathrm{m}$.

Figure 9 displays a scatter plot of $n_{t}$ versus $n_{0.4}$. Measurements obtained inside the polar vortex yield a very compact negative correlation with $n_{0.4}$ decreasing strongly as $n_{t}$ is increasing. Outside the vortex $n_{t}$ and $n_{0.4}$ are positively correlated but the correlation is more scattered than inside the vortex.

Typical aerosol size distributions for measurements at $19 \mathrm{~km}$ altitude are compared in Fig. 10. Both size distributions peak near the smallest channel $(\mathrm{d}=0.4 \mu \mathrm{m})$, but these peaks are likely to be caused by an instrumental under estimation of the particles in the lowest channel. The peaks therefore probably do not represent a maximum of the aerosol size distribution. For all channels the absolute concentrations measured inside the polar vortex are much smaller than those outside. Nevertheless, from the higher total particle concentrations $n_{t}$ measured inside the polar vortex compared to outside (cf. Fig. 3) we conclude that for some aerosol sizes $<0.4 \mu \mathrm{m}$ the absolute concentrations inside the vortex have to be higher than the concentrations

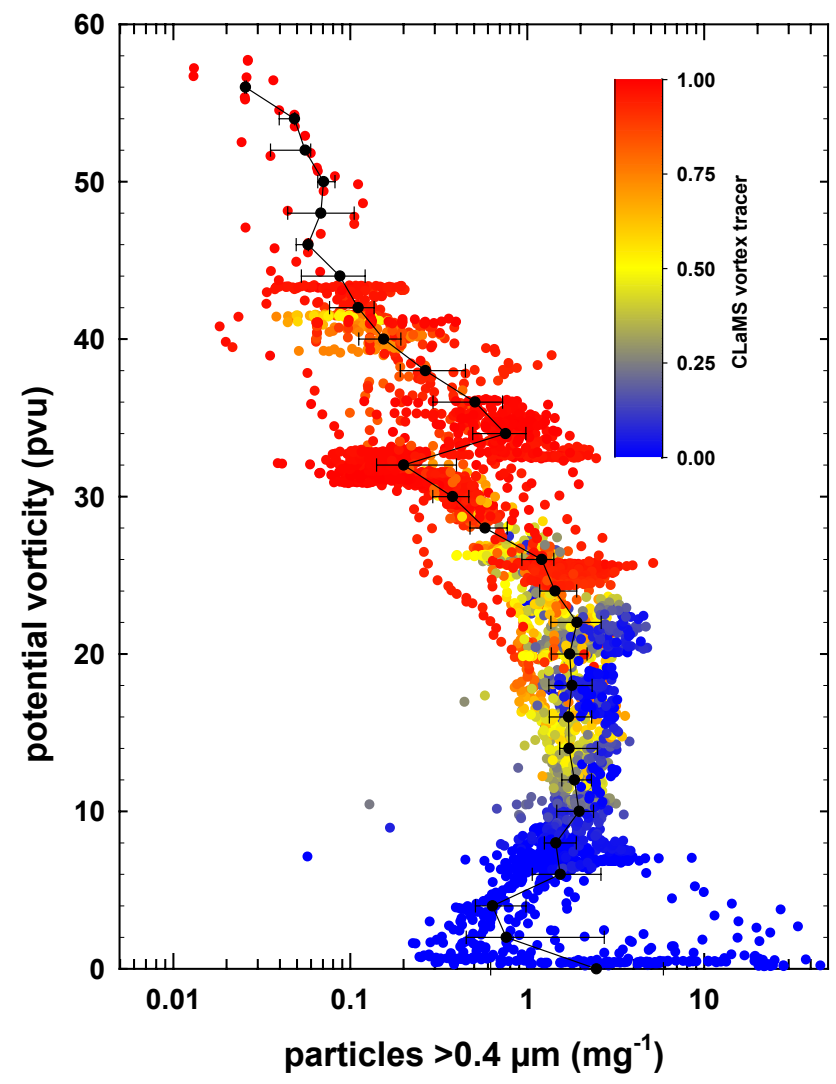

Fig. 8. Mixing ratio of particles $>0.4 \mu \mathrm{m}$ per mg air as a function of potential vorticity with vortex tracer indicated by color coding. Median values binned by 2 pvu intervals with $25 / 75$-percentiles included.

outside the vortex; i.e., continuing the size distributions to smaller particle diameters the black curve would have to rise above the red curve at some point in Fig. 10.

The measured size distributions and the concentrations $n_{0.4}$ compare well with previous measurements in the winter polar stratosphere by Borrmann et al. (2000a). These authors measured similar size distributions for situations inside and outside the Arctic polar vortex and also a distinct decrease of $n_{0.4}$ with increasing altitude was observed for altitudes $>19 \mathrm{~km}$ for a measurement flight $(29$ December 1996) conducted inside the polar vortex $\left(n_{0.4} \approx 0.1 \mathrm{~cm}^{-3}\right.$ at $19.5 \mathrm{~km}$, and $n_{0.4} \approx 0.02 \mathrm{~cm}^{-3}$ at $20.5 \mathrm{~km}$ ). Similarly, Hofmann et al. (1989) reported a strong decrease of the number concentration of particles $>0.3 \mu \mathrm{m}$ in the Antarctic stratosphere at altitudes $>18 \mathrm{~km}$. They identified this flank as the upper edge of the Junge layer which is shifted downward by several $\mathrm{km}$ in the Antarctic compared to mid-latitudes. Furthermore, satellite observations of the aerosol extinction by the optically active particles confirm these findings. The aerosol extinction profiles in the Arctic and Antarctic polar vortex are shifted downward by several $\mathrm{km}$ (McCormick et al., 1983; Kent et al., 1985; Thomason et al., 1997). 


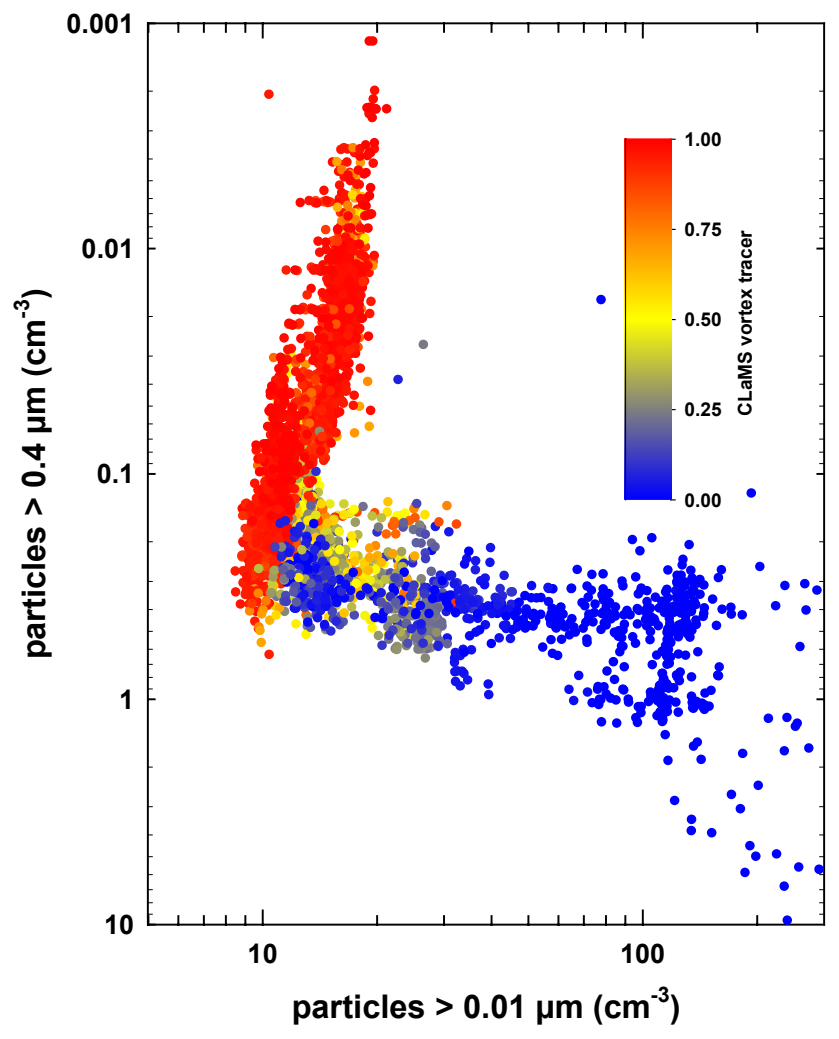

Fig. 9. Number concentration of particles $>0.4 \mu \mathrm{m}$ (FSSP-300) versus total particle concentration $>0.01 \mu \mathrm{m}$ (COPAS). Vortex tracer values are color coded.

\subsection{Particles in the lowermost stratosphere}

In this section we will focus on the particle measurements in the lowermost stratosphere. Especially the sources of the high variability of the particle measurements at altitudes below $14 \mathrm{~km}$ will be discussed (cf. Fig. 2). We chose to study two exemplary flights (23 January, 8 February) including detailed trajectory analyses to investigate the origin of the air masses in order to explain the high variability of our observations. The lowermost stratosphere is defined as the transition region between the local tropopause and the $380 \mathrm{~K}$ potential temperature level (Holton et al., 1995).

Figure 11a shows the vertical profile of the particle measurements along with other measurements for the flight of 23 January 2003. The tracers ozone $\left(\mathrm{O}_{3}\right), \mathrm{N}_{2} \mathrm{O}, \mathrm{CFC}-11$ and water vapor $\left(\mathrm{H}_{2} \mathrm{O}\right)$ are shown, along with temperature and potential vorticity profiles. Ascent and descent of this flight were conducted in or below the polar vortex. In this case the tropopause was located at $\sim 290 \mathrm{~K}$. Total particle concentrations $n_{t}$ range at $50-100 \mathrm{~cm}^{-3}$ for potential temperatures of $310-350 \mathrm{~K}$ and decrease below $50 \mathrm{~cm}^{-3}$ above $350 \mathrm{~K}$. Similarly, $\mathrm{H}_{2} \mathrm{O}$ decreases continuously up to $350 \mathrm{~K}$ and remains relatively constant at $3.5-4.5 \mathrm{ppmv}$ above $350 \mathrm{~K} . \mathrm{N}_{2} \mathrm{O}$ and CFC-11 decrease both to $<90 \%$ of their tropospheric values

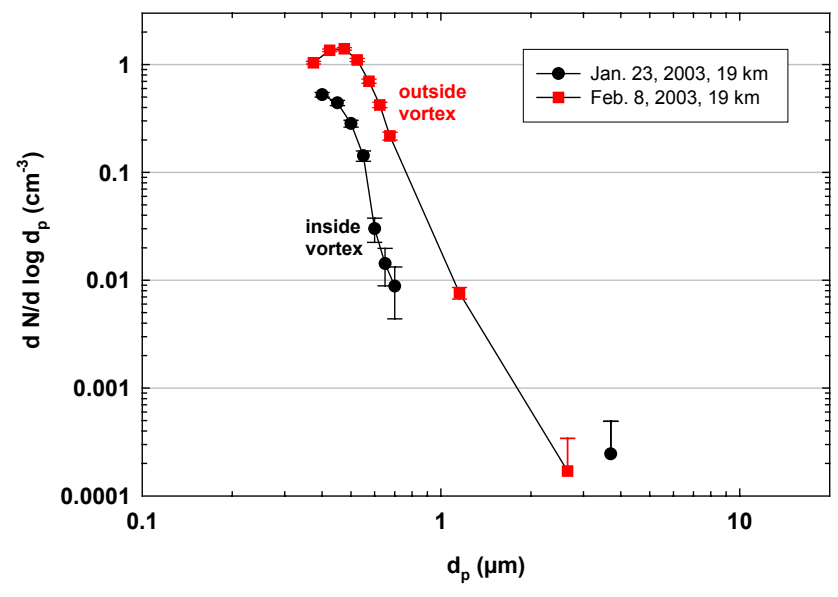

Fig. 10. Particle number size distributions measured at $19 \mathrm{~km}$ altitude for the flights of 23 January (inside polar vortex) and 8 February 2003, (outside polar vortex). Measurements are integrated over approximately one hour to increase statistical accuracy. Statistical uncertainties are indicated by error bars.

at $>350 \mathrm{~K}$. For the flight of 8 February 2003, the corresponding quantities are shown in Fig. 11b. This flight showed much higher particle concentrations below $370 \mathrm{~K}$. Here ascent and descent were conducted outside the polar vortex. From the particle measurements during the descent of the flight of 8 February it can be seen that the distinct step structure is observed by all three unheated channels of the two COPAS counters. An almost identical step structure is also observed during ascent. Ozone, $\mathrm{N}_{2} \mathrm{O}, \mathrm{CFC}-11, \mathrm{H}_{2} \mathrm{O}$ and temperature also show profiles that are very similar for ascent and descent despite a time span of $3.5 \mathrm{~h}$ between the ascent from and the descent to Kiruna. In contrast to the unheated channels the heated channel of COPAS does not show a distinct step structure and the fraction of non-volatile particles drops from $20-40 \%$ above the step to $5-15 \%$ below $350 \mathrm{~K}$. Therefore we conclude that most of the particles below $350 \mathrm{~K}$ are likely to be pure sulfuric acid/water particles.

Recently, several publications discussed the existence of a so-called "mixing layer" or "tropopause following transition layer" extending typically $2-3 \mathrm{~km}$ (or $\sim 25 \mathrm{~K}$ in potential temperature) above the local tropopause (e.g. Fischer et al., 2000; Hoor et al., 2002). Due to the influence of extratropical cross-tropopause transport of tropospheric air on the tracer abundances, the tracer-tracer relationships in the tropopause following transition layer deviate significantly from those typically observed in the remaining lowermost stratosphere. From Fig. $11 \mathrm{~b}$ it can be seen that such a tropopause following transition layer may be defined from the vertical profiles of ozone and water vapor. Above the local tropopause at $313 \mathrm{~K}$, defined by the change in temperature lapse rate, ozone and water mixing ratios change continuously from tropospheric to stratospheric mixing ratios within a mixing layer between 313 and $348 \mathrm{~K}$. But these tracers do not reveal 

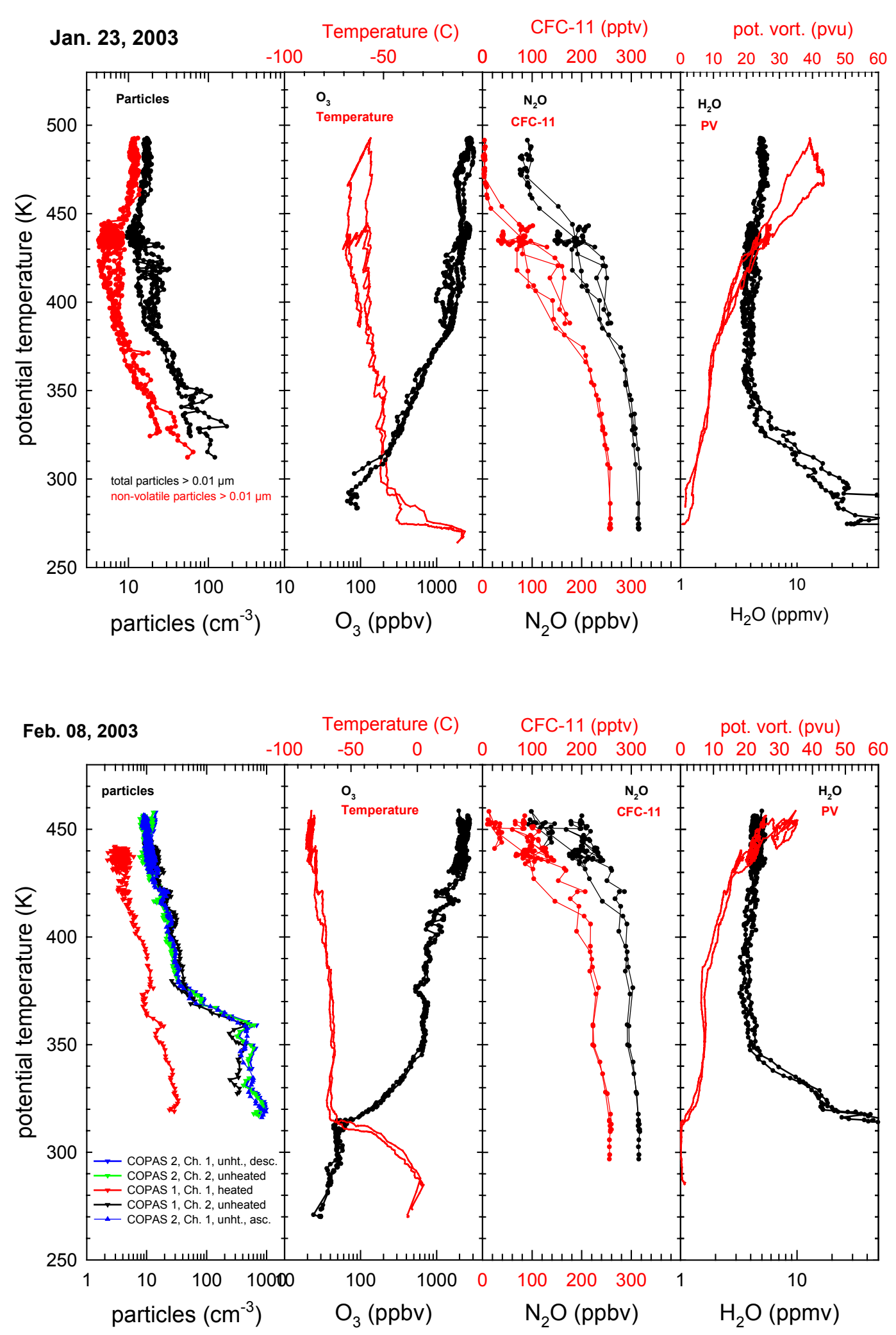

Fig. 11. Measurements for flight of 23 January 2003. Potential temperature profiles for total particle concentration $\mathrm{n}_{t}$, non-volatile particle concentration $\mathrm{n}_{n v}$, ozone and temperature, $\mathrm{N}_{2} \mathrm{O}$ and CFC-11, potential vorticity and $\mathrm{H}_{2} \mathrm{O}$ are shown (a). Same for 8 February 2003, both COPAS instruments were operated during this flight and data from all four channels are shown (b). 
distinct changes at 360-370 $\mathrm{K}$ where the steep change in particle concentration occurs. The $\mathrm{N}_{2} \mathrm{O}$ and CFC-11 profiles on the other hand decrease slowly with increasing altitude and mixing ratios $>90 \%$ of the tropospheric $\mathrm{N}_{2} \mathrm{O}$ and CFC-11 values are measured even above $400 \mathrm{~K}$ potential temperature.

We investigated in how far the high particle concentration in the region between 330 and $370 \mathrm{~K}$ for 8 February could be caused by quasi-horizontal transport of upper tropospheric, aerosol-rich air from mid, subtropical or even tropical latitudes. Tropospheric air entering the stratosphere isentropically at lower latitudes could have been transported to higher latitudes before sampling. For the two flights of 23 January and 8 February, 30-day backward trajectories of ensembles of air parcels ending near the Geophysica's flight track were calculated separately for $10-\mathrm{K}$ potential temperature segments between 330 and $400 \mathrm{~K}$. These calculations were performed with the trajectory tool LAGRANTO (Wernli and Davies, 1997) using wind and temperature fields from the operational ECMWF analyses with a horizontal resolution of 1 degree. These trajectories are shown in Fig. 12 for the $355-365 \mathrm{~K}$ segments of the two flights. The trajectories of 23 January show that the air parcels are continuously located north of $40^{\circ} \mathrm{N}$ and are of strictly stratospheric origin. For 8 February, trajectories point to a more southerly origin of the air masses around $20^{\circ} \mathrm{N}$ and the trajectories do not come close to the North Pole. They indicate in this case a recent tropospheric influence on the air masses sampled during ascent and descent which is illustrated more closely in Fig. 13. This figure shows the position of air parcels (circles) on 10 January which will end at Geophysica's position between 325 and $335 \mathrm{~K}$ (Fig. 13a) and between 355 and $365 \mathrm{~K}$ (Fig. 13b) on 8 February. The average potential temperature of the displayed air parcels on 10 January is $342 \mathrm{~K}$ in case (a) and $393 \mathrm{~K}$ for case (b), respectively. For these potential temperatures the PV maps are plotted with the tropopause defined by 2 pvu indicated by a thick black line. It can be seen in (a) that at this time and for this flight level many of the air parcels are located in the troposphere or in the tropopause region making a tropospheric influence obvious. In case (b), indeed, for a few air parcels a tropospheric influence is also evident. For instance over Arabia, some air parcels that are later transported to the Geophysica's flight path are located in a cut-off of tropospheric air. It is also conceivable that some of the air masses initially originated from the tropical tropopause layer. Equivalent graphs for $\Theta>365 \mathrm{~K}$ look very similar to Fig. 13b. The findings from the trajectory studies are further supported by the profiles of the tracers $\mathrm{N}_{2} \mathrm{O}$ and CFC-11 which attain high mixing ratios within $90 \%$ of their tropospheric values throughout the whole LS (Fig. 11b). Their mixing ratios are decreasing with increasing $\Theta$ much slower than for the flight of 23 January (cf. Fig. 11a), illustrating again that the air masses encountered during ascent and descent of 8 February have experienced a significant recent tropospheric influence. The fact that $\mathrm{H}_{2} \mathrm{O}$ decreases to values below 5 ppmv at $>350 \mathrm{~K}$ may be explained by signif-
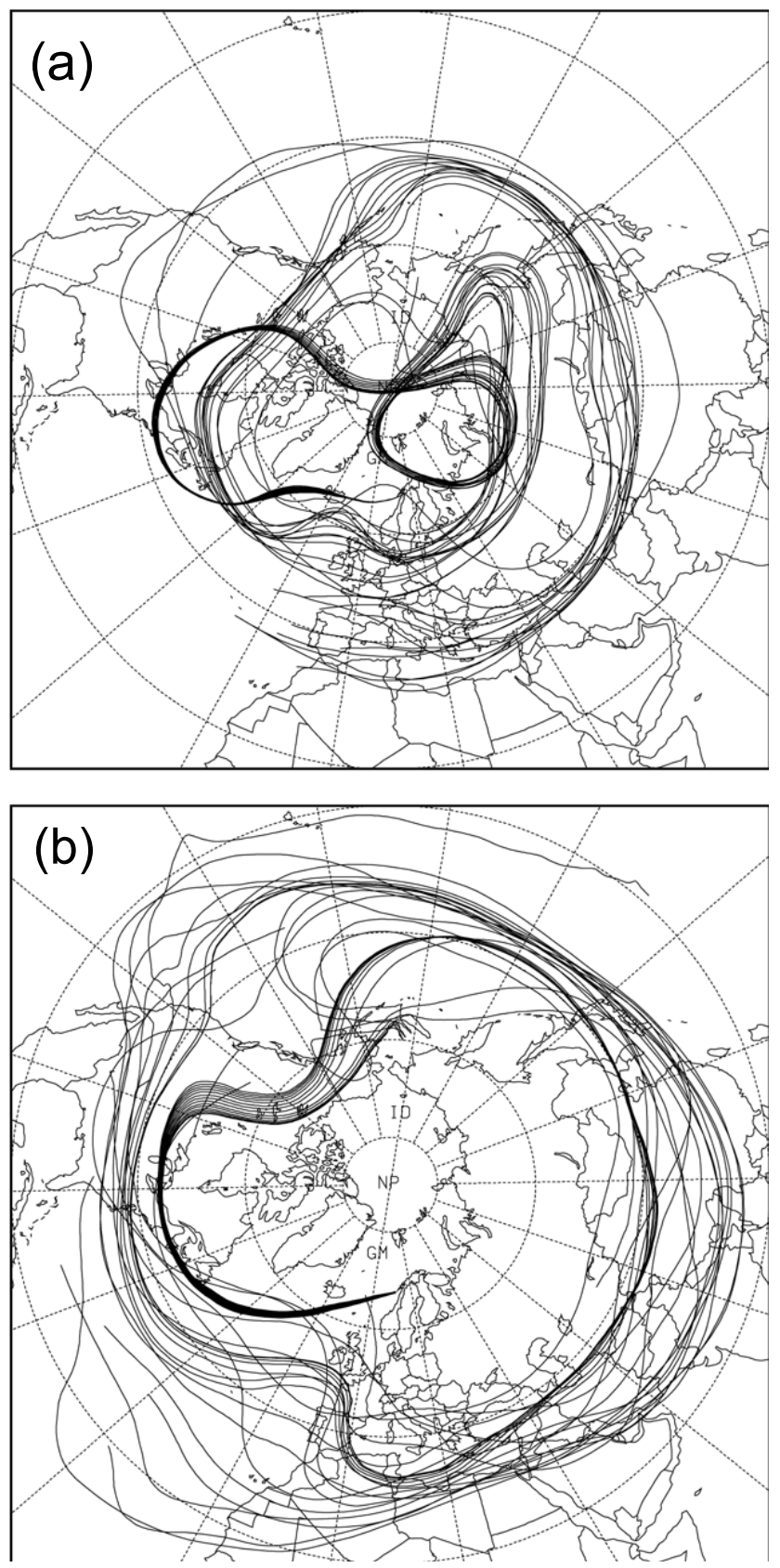

Fig. 12. Ensemble of 20-day backward trajectories for Geophysica's position at $360 \mathrm{~K}$ for 23 January 2003 (a). Same for 8 February 2003 (b).

icant reduction of $\mathrm{H}_{2} \mathrm{O}$ by freeze-drying processes when the air masses entered the stratosphere.

In conclusion, the trajectories show that for the flight of 23 January, when particle concentrations are low throughout the LS, the air masses are of stratospheric origin only. On the other hand, a tropospheric influence of potentially aerosol-rich air can clearly be discerned for the air masses measured in the LS during ascent and descent on 8 February. 

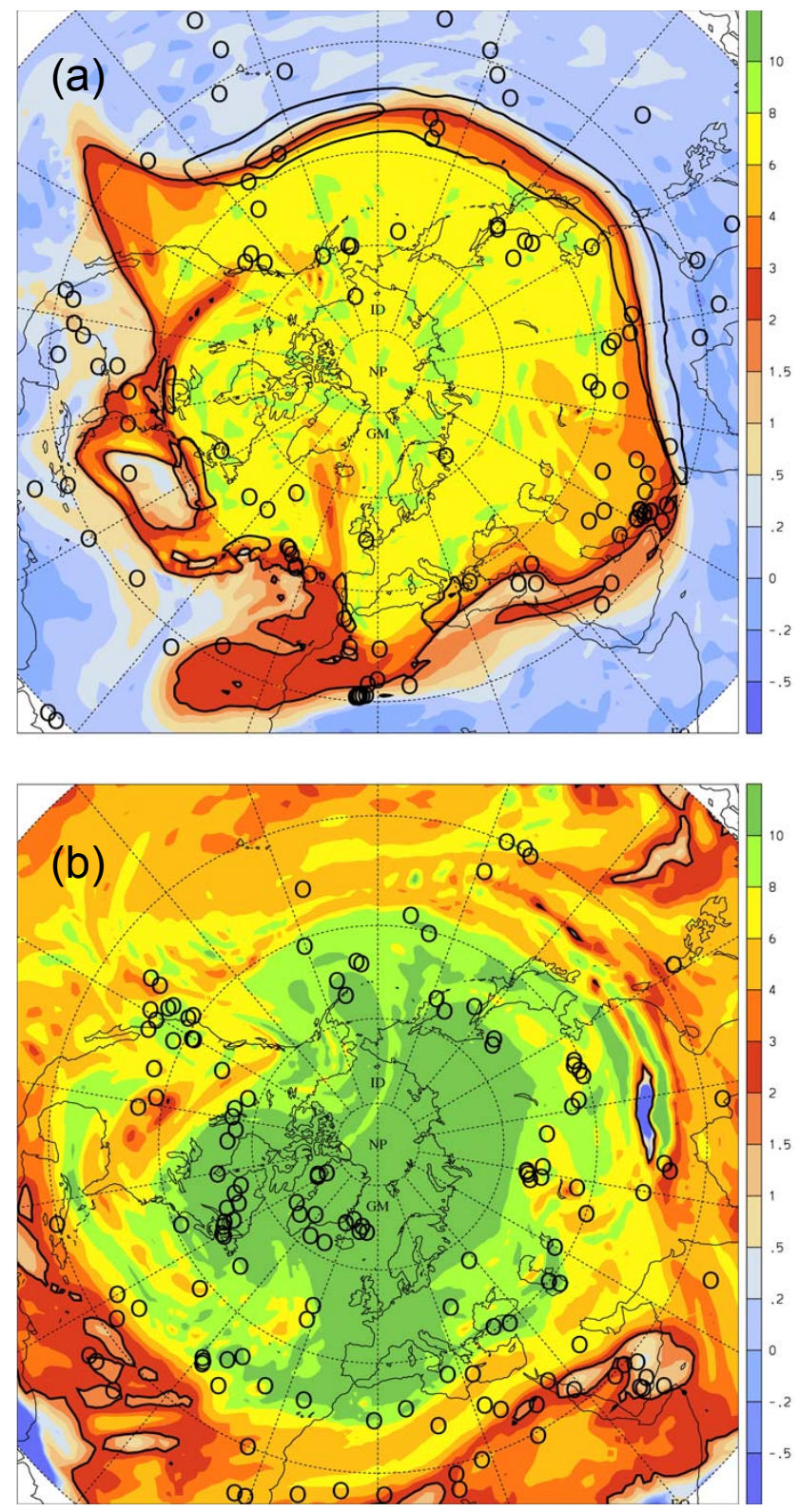

Fig. 13. Circles show positions of air parcels on 10 January 2003, that end near Geophysica's position at $330 \mathrm{~K}$ on 8 February 2003. Colors indicate PV on the isentropic surface for the air parcels average potential temperature $\Theta$ of $342 \mathrm{~K}$. Thick black line at 2 PVU indicates the tropopause, thick green lines indicate horizontal wind speed isolines of 60 and $80 \mathrm{~m} \mathrm{~s}^{-1}$ (a). Same for air parcels ending at $360 \mathrm{~K}$ on 8 February 2003. PV map is shown at $392 \mathrm{~K}$ which corresponds to the average $\Theta$ of the air parcels (b).

Nevertheless it is difficult to explain the origin of the step in particle concentration around $365 \mathrm{~K}$ by the tropospheric influence alone because there is no distinct difference in the history of the air masses below and above $365 \mathrm{~K}$. A possibility to explain the high particle concentrations in the LS is formation of new particles. Nucleation of new particles has been observed in the polar and mid-latitude lowermost stratosphere (Lee et al., 2003; de Reus et al., 1999; Hermann et al., 2003). Lee et al. (2003) were able to explain the observed fresh particles with the help of a model by Lovejoy et al. (2004), as being caused by ion-induced nucleation of sulfuric acid and water. The observed high fraction of volatile particles in the layer favors the interpretation of recent nucleation of sulfuric acid and water, potentially induced by an ion process. Unfortunately no precursor gases like $\mathrm{SO}_{2}$ and $\mathrm{OH}$ or gaseous $\mathrm{H}_{2} \mathrm{SO}_{4}$ were measured onboard Geophysica and the temperature difference between saturator and condenser of the unheated COPAS channels was the same for all channels. Therefore we are currently not able to support this interpretation by other measurements or modeling efforts. It is interesting to note that a very similar particle layer in the LS with concentrations reaching up to $450 \mathrm{~cm}^{-3}$ has been observed on a balloon flight from Kiruna on 19 January 1997 (Borrmann et al., 2000). In this flight concentrations also decrease markedly above $14 \mathrm{~km}$ altitude very similar to our observations, but the authors did not comment on this feature explicitly.

Airborne Measurements by Baumgardner et al. (2004) which were also conducted in January and February 2003 in the Arctic lowermost stratosphere $(9-12 \mathrm{~km})$ indicate an unexpectedly high fraction of typically $>50 \%$ of lightabsorbing particles composed predominantly of black carbon. Additionally, the typical fraction $f$ of non-volatile residual particles is reported to be $\sim 50 \%$. These authors attribute this high fraction of light absorbing material to lower latitude tropospheric transport (Baumgardner et al., 2004). Their interpretation is therefore in agreement with our interpretation of the high $\mathrm{CN}$ concentration, but the high fraction of non-volatile residual particles is in contrast to our findings of typically lower fractions around $10 \%$ at these altitudes.

\section{Summary}

Two automated Condensation Nucleus Counters for operation aboard the high altitude research aircraft Geophysica have been developed and characterized. The instruments operated successfully during two Arctic measurement campaigns in winter 2003. Particle number concentrations measured were typical for Arctic stratosphere conditions. At altitudes around $19 \mathrm{~km}$ the total particle concentration $n_{t}$ is found to increase from $\sim 10 \mathrm{~cm}^{-3}$ outside the vortex to $\sim 20 \mathrm{~cm}^{-3}$ inside the vortex. From the correlation with the stratospheric tracers $\mathrm{N}_{2} \mathrm{O}$ and CFC- 11 this increase is attributed to aerosol nucleation in the stratosphere above. The nucleation might be rather a heterogeneous than a homogeneous process, most likely condensation of $\mathrm{H}_{2} \mathrm{SO}_{4}$ and $\mathrm{H}_{2} \mathrm{O}$ on cores of meteoric material because of the observed low variability of the $\mathrm{N}_{2} \mathrm{O}$-particle correlation and because of the high fraction $f$ of non-volatile residual particles found in the vortex. 
Inside the polar vortex a significantly higher fraction of non-volatile particles is measured than outside the vortex. The fraction $f$ ranges at 58 to 76 percent inside the vortex and around 12-45 percent outside the vortex. The difference is most likely caused by downward transport of meteoric material from the mesosphere inside the vortex and gives experimental evidence for the transport of mesospheric air even down to the lowest levels of the polar vortex. The fraction of non-volatile residual particles also serves as an experimentally accessible estimate of a vortex tracer. Besides meteoric smoke, particles of different nature such as light absorbing soot particles (Baumgardner et al., 2002), may influence the measurement of $f$ and therefore limit the use of $f$ as a vortex tracer.

The correlation of large particles $>0.4 \mu \mathrm{m}$ with potential vorticity revealed a strong decrease of $n_{0.4}$ with increasing potential vorticity inside the polar vortex.

In the lowermost stratosphere $(\Theta \leq 360 \mathrm{~K})$ particle concentrations $n_{t}$ of several hundred per $\mathrm{cm}^{-3}$ were frequently observed. Air masses in which these high concentrations were found had originated partly in the upper troposphere at lower latitudes and had been transported quasi-horizontally to the higher latitudes where our measurements were performed. The high particle concentrations $n_{t}$ in these air masses may be explained by transport of particle-rich air from the lower latitude UT and/or by recent particle nucleation in the lowermost stratosphere.

In the future, three unheated channels of the COPAS instruments will be operated at different saturator temperatures to allow for the detection of ultrafine particles. Further volatility studies will be of interest to study the cycling of meteoric material in the stratosphere.

Acknowledgements. We are thankful to C. A. Brock and J. C. Wilson for the original CN-Counter designs. We thank T. Böttger, F. Helleis, W. Schneider, A. Thomas, A. Adriani, M. Viterbini, F. Stroh and the entire Geophysica team. We thank M. Hermann for helpful discussion and his engagement and guidance in characterizing the COPAS counters. Research and development was funded by the EC under the Project Numbers EVR1-CT2001-40020, EVK2-CT-2001-00119, ENV4-CT95-0143, and ENV4-CT96-0163. Further financial support was provided by the Johannes-Gutenberg-University and the Max-Planck-Institute for Chemistry in Mainz, Germany.

Edited by: K. Carslaw

\section{References}

Arnold, F., Curtius, J., Spreng, S., and Deshler, T.: Stratospheric aerosol sulfuric acid: First direct in situ measurements using a novel balloon-based mass spectrometer apparatus, J. Atmos. Chem., 30, 3-10, 1998.

Baumgardner, D., Dye, J. E., Gandrud, B. W., and Knollenberg, R. G.: Interpretation of measurements made by the Forward Scattering Spectrometer Probe (FSSP-300) during the Airborne Arc- tic Stratospheric Expedition, J. Geophys. Res., 97, 8035-8046, 1992.

Baumgardner, D., Kok, G., and Raga, G.: Warming of the Arctic lower stratosphere by light absorbing particles, Geophys. Res. Lett., 31, L06117, doi:10.1029/2003GL018883, 2004.

Bigg, E. K., Ono, A., and Thompson, W. J.: Aerosols at altitudes between 20 and $27 \mathrm{~km}$, Tellus, 22, 550-563, 1970.

Borrmann, S., Dye, J. E., Baumgardner D., Wilson, J. C., Jónsson, H. H., Brock, C. A., Loewenstein, M., Podolske, J. R., Ferry, G V., and Barr, K. S.: In-situ measurements of changes in stratospheric aerosol and the $\mathrm{N}_{2} \mathrm{O}$-aerosol relationship inside and outside of the polar vortex, Geophys. Res. Lett., 20, 2559-2562, 1993.

Borrmann, S., Thomas, A., Rudakov, V., Yushkov, V., Lepuchov, B., Deshler, T., Vinnichenko, N., Khattatov, V., and Stefanutti, L.: In-situ aerosol measurements in the northern hemispheric stratosphere of the 1996/7 winter on the Russian M-55 Geophysica high altitude research aircraft, Tellus, 52B, 1088-1103, 2000a.

Borrmann, S., Luo, B., and Mishchenko, M.: The application of the T-matrix method to the measurement of aspherical particles with forward scattering optical particle counters, J. Aerosol Sci., 31, 789-799, 2000b.

Brock, C. A., Hamill, P., Wilson, J. C., Jonsson, H. H., and Chan, K. R.: Particle formation in the upper tropical troposphere: A source of particles for the stratospheric aerosol, Science, 270, 1650-1653, 1995.

Brock, C. A., Schröder, F., Kärcher, B., Petzold, A., Busen, R., and Fiebig, M.: Ultrafine particle size distributions measured in aircraft exhaust plumes, J. Geophys. Res., 105, 26 555-26567, 2000.

Cziczo, D. J., Thomson, D. S., and Murphy, D. M.: Ablation, flux, and atmospheric implications of meteors inferred from stratospheric aerosol, Science, 291, 1772-1775, 2001.

de Reus, M., Ström, J., Hoor, P., Lelieveld, J., and Schiller, C.: Particle production in the lowermost stratosphere by convective lifting of the tropopause, J. Geophys. Res., 104, 23 935-23 940, 1999.

Deshler, T., Johnson, B. J., and Rozier, W. R.: Balloonborne measurements of Pinatubo aerosol during 1991 and 1992 at $41^{\circ} \mathrm{N}$ : Vertical profiles, size distribution, and volatility, Geophys. Res. Lett., 20, 1435-1438, 1993.

Deshler, T., Hervig, M. E., Hofmann, D. J., Rosen, J. M., and Liley, J. B.: Thirty years of in situ stratospheric aerosol size distribution measurements from Laramie, Wyoming $\left(41^{\circ} \mathrm{N}\right)$, using balloon-borne instruments, J. Geophys. Res., 108, 4167, doi:10.1029/2002JD002514, 2003.

Dye, J. E., Baumgardner, D., Gandrud, B. W., Kawa, S. R., Kelly, K. K., Loewenstein, M., Ferry, G. V., Chan, K. R., and Gary, B. L.: Particle size distributions in Arctic polar stratospheric clouds, growth, and freezing of sulfuric acid droplets, and implications for cloud formation, J. Geophys. Res., 97, 8015-8034, 1992.

Engel, A., Möbius, T., Haase, H.-P., Bönisch, H., Wetter, T., Schmidt, U., Levin, I., Reddmann, T., Oelhaf, H., Wetzel, G., Grunow, K., Huret, N., and Pirre, M.: On the observation of mesospheric air inside the arctic stratospheric polar vortex in early 2003, Atmos. Chem. Phys. Discuss., 5, 7457-7496, 2005, SRef-ID: 1680-7375/acpd/2005-5-7457.

Fischer, H., Wienhold, F. G., Hoor, P., Bujok, O., Schiller, C., Siegmund, P., Ambaum, M., Scheeren, H. A., and Lelieveld, J.: 
Tracer correlations in the northern high latitude lowermost stratosphere: Influence of cross-tropopause mass exchange, Geophys. Res. Lett., 27, 97-100, 2000.

Fisher, M, O’Neill, A., and Sutton, R.: Rapid descent of mesospheric air into the stratospheric polar vortex, Geophys. Res. Lett., 20, 1267-1270, 1993.

Gabrielli, P., Barbante, C., Plane, J. M. C., Varga, A., Hong, S., Cozzi, G., Gaspari, V., Planchon, F. A. M., Cairns, W., Ferrari, C., Crutzen, P., Cescon, P., and Boutron, C. F.: Meteoric smoke fallout over the Holocene epoch revealed by iridium and platinum in Greenland ice, Nature, 432, 1011-1014, 2004.

Hamill, P., Toon, O. B., and Turco, R. P.: Aerosol nucleation in the winter Arctic and Antarctic stratospheres, Geophys. Res. Lett., 17, 417-420, 1990.

Hamill, P., Jensen, E. J., Russell, P. B., and Baumann, J. J.: The life cycle of stratospheric aerosol particles, Bull. Am. Met. Soc., 78, 1395-1410, 1997.

Hermann, M. and Wiedensohler, A.: Counting efficiency of condensation particle counters at low-pressures with illustrative data from the upper troposphere, J. Aerosol Sci., 32, 975-991, 2001.

Hermann, M., Heintzenberg, J., Wiedensohler, A., Zahn, A., Heinrich, G., and Brenninkmeijer, C. A. M.: Meridional distributions of aerosol particle number concentrations in the upper troposphere and lower stratosphere obtained by Civil Aircraft for Regular Investigation of the Atmosphere Based on an Instrument Container (CARIBIC) flights, J. Geophys. Res., 108, 4114, doi:10.1029/2001JD001077, 2003.

Hofmann, D. J.: Balloon-borne measurements of middle atmosphere aerosols and trace gases in Antarctica, Rev. Geophys., 26, 113-130, 1988.

Hofmann, D. J.: Measurement of the condensation nuclei profile to $31 \mathrm{~km}$ in the Arctic in January 1989 and comparison with Antarctic measurements, Geophys. Res. Lett., 17, 357-360, 1990.

Hofmann, D. J. and Rosen, J. M.: Antarctic observations of stratospheric aerosol and high altitude condensation nuclei following the El Chichon eruption, Geophys. Res. Lett., 12, 13-16, 1985.

Hofmann, D. J., Rosen, J. M., Harder, J. W., and Hereford, J. $\mathrm{V}$ :: Balloon-borne measurements of aerosol condensation nuclei, and cloud particles in the stratosphere at McMurdo Station, Antarctica, during the spring of 1987, J. Geophys. Res., 94, $11253-11269,1989$.

Holton, J. R., Haynes, P. H., McIntyre, M. E., Douglass, A. R., Rood, R. B., and Pfister, L.: Stratosphere-troposphere exchange, Rev. Geophys., 33, 403-439, 1995.

Hoor, P., Fischer, H., Lange, L., Lelieveld, J., and Brunner, D.: Seasonal variations of a mixing layer in the lowermost stratosphere as identified by the $\mathrm{CO}-\mathrm{O}_{3}$ correlation from in situ measurements, J. Geophys. Res., 107, 4044, doi:10.1029/2000JD000289, 2002.

Hunten, D. M., Turco, R. P., and Toon, O. B.: Smoke and dust particles of meteoric origin in the mesosphere and stratosphere, J. Atmos. Sci., 37, 1343-1357, 1980.

Junge, C. E. and Manson, J. E.: Stratospheric aerosol studies, J. Geophys. Res., 66, 2163-2182, 1961.

Kent, G. S., Trepte, C. R., Farrukh, U. O., and McCormick, M. P.: Variation in the stratospheric aerosol associated with the north cyclonic polar vortex as measured by the SAM II satellite sensor, J. Atmos. Sci., 42, 1536-1551, 1985.

Konopka, P., Steinhorst, H. M., Grooss, J. U., Günther, G., Müller,
R., Elkins, J. W., Jost, H. J., Richard, E., Schmidt, U., Toon, G., and McKenna, D. S.: Mixing and ozone loss in the 1999-2000 Arctic vortex: Simulations with the three-dimensional Chemical Lagrangian Model of the Stratosphere (CLaMS), J. Geophys. Res., 109, D02315, doi:10.1029/2003JD003792, 2004.

Lee, S.-H., Reeves J. M., Wilson, J. C., Hunton, D. E., Viggiano, A. A., Miller, T. M., Ballenthin, J. O., and Lait, L. R.: Particle formation by ion nucleation in the upper troposphere and lower stratosphere, Science, 301, 1886-1889, 2003.

Lovejoy, E. R., Curtius, J., and Froyd, K. D.: Atmospheric ioninduced nucleation of sulfuric acid and water, J. Geophys. Res., 109, D08204, doi:10.1029/2003JD004460, 2004.

Mills, M. J., Toon, O. B., and Solomon, S.: A 2D microphysical model of the polar stratospheric CN layer, Geophys. Res. Lett., 26, 1133-1136, 1999.

McCormick, M. P., Trepte, C. R., and Kent, G. S.: Spatial changes in the stratospheric aerosol associated with the north polar vortex, Geophys. Res. Lett., 10, 941-944, 1983.

McKenna, D. S., Konopka, P., Grooß, J.-U., Günther, G., Müller, R., Spang, R., Offermann, D., and Orsolini, Y.: A new Chemical Lagrangian Model of the Stratosphere (CLaMS): I. Formulation of advection and mixing, J. Geophys. Res., 107, 4309, doi:10.1029/2000JD000114, 2002.

Murphy, D. M. and Fahey, D. W.: An estimate of the flux of stratospheric reactive nitrogen and ozone into the troposphere, J. Geophys. Res., 99, 5325-5332, 1994.

Murphy, D. M., Thomson, D. S., and Mahoney, M. J.: In situ measurements of organics, meteoritic material, mercury, and other elements in aerosols at 5 to 19 kilometers, Science, 282, 1664 1669, 1998.

Nash, E. R., Newman, P. A., Rosenfield, J. E., and Schoeberl, M. R.: An objective determination of the polar vortex using Ertel's potential vorticity, J. Geophys. Res., 101, 9471-9478, 1996.

Prather, M. J. and Rodriguez, J. M.: Antactic ozone: Meteoritic control of $\mathrm{HNO}_{3}$, Geophys. Res. Lett., 15, 1-4, 1988.

Plane, J. M. C.: Atmospheric chemistry of meteoric metals, Chem. Rev., 103, 4963-4984, 2003.

Plumb, R. A. and Ko, M. K. W.: Interrelationships between mixing ratios of long-lived stratospheric constituents, J. Geophys. Res., 97, $10145-10156,1992$.

Plumb, R. A., Heres, W., Neu, J. L., Mahowald, N. M., del Corral, J., Toon, G. C., Ray, E., Moore, F., and Andrews, A. E.: Global tracer modeling during SOLVE: High-latitude descent and mixing, J. Geophys. Res., 107, 8309, doi:10.1029/2001JD001023, 2002; (printed 108(D5), 2003).

Renard, J.-B., Berthet, G., Robert, C., Chartier, M., Pirre, M., Brogniez, C., Herman, M., Verwaerde, C., Balois, J.-Y., Ovarlez, J., Ovarlez, H., Crespin, J., and Deshler, T.: Optical and physical properties of stratospheric aerosols from balloon measurements in the visible and near-infrared domains. II., Comparison of extinction, reflectance, polarization, and counting measurements, Appl. Optics, 41, 7540-7549, 2002.

Renard, J.-B., Ovarlez, J., Berthet, G., Fussen, D., Vanhellemont, F., Brogniez, C., Hadamcik, E., Chartier, M., and Ovarlez, H.: Optical and physical properties of stratospheric aerosols from balloon measurements in the visible and near-infrared domains. III. Presence of aerosols in the middle stratosphere, Appl. Optics, 44, 4086-4095, 2004.

Rosen, J. M.: The boiling point of stratospheric aerosols, J. Appl. 
Met., 10, 1044-1046, 1971.

Rosen, J. M., Hofmann, D. J., and Gringel, W.: Measurements of Ion Mobility to $30 \mathrm{~km}$, J. Geophys. Res., 90, 5876-5884, 1985.

Schlager, H. and Arnold, F.: Balloon-borne composition measurements of stratospheric negative ions and inferred sulfuric acid vapor abundances during the MAP/GLOBUS 1983 campaign, Planet. Space Sci., 35, 693-701, 1987.

Steinhorst, H.-M., Konopka, P., Günther, G., and Müller, R.: How permeable is the edge of the Arctic vortex: Model studies of winter 1999-2000, J. Geophys. Res., 110, D06105, doi:10.1029/2004JD005268, 2005.

Thomas, A., Borrmann, S., Kiemle, Ch., Cairo, F., Volk, M., Beuermann, K., Lepuchov, B., Santacesaria, V., Matthey, R., Rudakov, V., Yushkov, V., MacKenzie, A. R., and Stefanutti, L.: In situ measurements of background aerosol and subvisible cirrus in the tropical tropopause region, J. Geophys. Res., 107, doi:10.1029/2001JD001385, 2002.

Thomason, L. W., Poole, L. R., and Deshler, T.: A global climatology of stratospheric aerosol surface area density deduced from Stratospheric Aerosol and Gas Experiment II measurements: 1984-1994, J. Geophys. Res., 102, 8967-8976, 1997.

Timmreck, C.: Three-dimensional simulation of stratospheric background aerosol: First results of a multiannual general circulation model simulation, J. Geophys. Res., 106, 28 313-28 332, 2001.

Turco, R. P., Toon, O. B., Hamill, P., and Whitten, R. C.: Effects of meteoric debris on stratospheric aerosols and gases, J. Geophys. Res., 86, 1113-1128, 1981.

Vaida, V., Kjaergaard, H. G., Hintze, P. E., and Donaldson, D. J.: Photolysis of sulfuric acid vapor by visible solar radiation, Science, 299, 1566-1568, 2003.

Voigt, C., Schlager, H., Luo, B. P., Dörnbrack, A., Roiger, A., Stock, P., Curtius, J., Vössing, H., Borrmann, S., Davies, S., Konopka, P., Schiller, C., Shur, G., and Peter, T.: Nitric acid trihydrate (NAT) formation at low NAT supersaturations, Atmos. Chem. Phys., 5, 1371-1380, 2005,

\section{SRef-ID: 1680-7324/acp/2005-5-1371.}

Wernli, H. and Davies, H. C.: A Lagrangian-based analysis of extratropical cyclones, 1 . The method and some applications, Q. J. R. Meteorol. Soc., 123, 467-489, 1997.

Wilson, J. C., Hyun, J. H., and Blackshear, E. D.: The function and response of an improved stratospheric condensation nucleus counter, J. Geophys. Res., 88, 6781-6785, 1983.

Wilson, J. C., Loewenstein, M., Fahey, D. W., Gary, B., Smith, S. D., Kelly, K. K., Ferry, G. V., and Chan, K. R.: Observations of condensation nuclei in the airborne Antarctic ozone experiment: Implications for new particle formation and polar stratospheric cloud formation, J. Geophys. Res., 94, 16 437-16448, 1989.

Wilson, J. C., Stolzenburg, M. R., Clark, W. E., Loewenstein, M., Ferry, G. V., and Chan, K. R.: Measurement of condensation nuclei in the airborne Arctic stratospheric expedition: Observations of particle production in the polar vortex, Geophys. Res. Lett., 17, 361-364, 1990.

Wilson, J. C., Stolzenburg, M. R., Clark, W. E., Loewenstein, M., Ferry, G. V., Chan, K. R., and Kelly, K. K.: Stratospheric sulfate aerosol in and near the Northern Hemisphere polar vortex: The morphology of the sulfate layer, multimodal size distributions, and the effect of denitrification, J. Geophys. Res., 97, 79978013, 1992.

Zhao, J., Toon, O. B., and Turco, R. P.: Origin of condensation nuclei in the springtime polar stratosphere, J. Geophys. Res., 100, 5215-5227, 1995.

Zöger, M., Afchine, A., Eicke, N., Gerhards, M. T., Klein, E., McKenna, D. S., Morschel, U., Schmidt, U., Tan, V., Tuitjer, F., Woyke, T., and Schiller, C.: Fast in situ stratospheric hygrometers: A new family of balloon-borne and airborne Lyman- $\alpha$ photofragment fluorescence hygrometers, J. Geophys. Res., 104, 1807-1816, 1999. 